\title{
Revealing the Secrets of the Temple: The Value of Publishing Central Bank Interest Rate Projections
}

\author{
Glenn D. Rudebusch \\ Federal Reserve Bank of San Francisco \\ John C. Williams \\ Federal Reserve Bank of San Francisco
}

October 2006

Working Paper 2006-31

http://www.frbsf.org/publications/economics/papers/2006/wp06-31bk.pdf

The views in this paper are solely the responsibility of the authors and should not be interpreted as reflecting the views of the Federal Reserve Bank of San Francisco or the Board of Governors of the Federal Reserve System. 


\title{
Revealing the Secrets of the Temple: The Value of Publishing Central Bank Interest Rate Projections*
}

\author{
Glenn D. Rudebusch ${ }^{\dagger} \quad$ John C. Williams ${ }^{\ddagger}$
}

October 2006

\begin{abstract}
The modern view of monetary policy stresses its role in shaping the entire yield curve of interest rates in order to achieve various macroeconomic objectives. A crucial element of this process involves guiding financial market expectations of future central bank actions. Recently, a few central banks have started to explicitly signal their future policy intentions to the public, and two of these banks have even begun publishing their internal interest rate projections. We examine the macroeconomic effects of direct revelation of a central bank's expectations about the future path of the policy rate. We show that, in an economy where private agents have imperfect information about the determination of monetary policy, central bank communication of interest rate projections can help shape financial market expectations and may improve macroeconomic performance.
\end{abstract}

JEL classification codes: E52, E43

\footnotetext{
${ }^{*}$ For helpful comments, we thank Lars Svensson, Marvin Goodfriend, Øistein Røisland, and colleagues throughout the Federal Reserve System. Vuong Nguyen provided excellent research assistance. The views expressed in this paper are our own and not necessarily those of others at the Federal Reserve Bank of San Francisco.

${ }^{\dagger}$ Federal Reserve Bank of San Francisco; www.frbsf.org/economists/grudebusch; Glenn.Rudebusch@sf.frb.org.

${ }^{\ddagger}$ Federal Reserve Bank of San Francisco; John.C.Williams@sf.frb.org.
} 


\section{Introduction}

The modern approach to monetary policy stresses the importance of guiding and influencing the public's expectations about future central bank actions. In this forward-looking view of monetary policy, the current setting of the policy interest rate, which is an overnight or very short-term rate, is on its own of little importance for private agents' decisions about consumption, investment, labor supply, and price setting. Instead, those decisions are more importantly driven by expectations of future short rates, especially as embodied in longer-term interest rates and other asset prices (along with the appropriate adjustments for risk). That is, the current policy rate is most relevant to the extent it conveys information about future policy settings and influences longer-maturity interest rates. Accordingly, at its core, monetary policy can be considered a process of shaping the entire yield curve of interest rates in order to achieve various macroeconomic objectives.

The crucial role that private sector interest rate expectations play in macroeconomic stabilization naturally raises the question: How can central banks best guide private expectations of future monetary policy actions? In the past, central bankers typically assumed that the accumulated record of their past policy actions was the best means of such communication. In this view, actions spoke louder than words, and private agents, by examining past policy behavior, could uncover a systematic policy pattern or rule that would be useful in predicting future policy actions. Recently, however, there is a new appreciation of the value of good communication as an accompaniment to good policy actions, and as a result, some central banks have started to place more importance on signaling their intentions for future policy. In practice, much of this central bank signaling of future policy intentions is implicit or indirect-essentially, a process of suggesting the future policy path by revealing information other than the future policy path. For example, some inflation-targeting central banks provide descriptions of their macroeconomic models and objectives as well as their current assessments of the state of the economy, but it is left to the public to infer the future policy path that is consistent with this information. A common such communication strategy is to publish an economic projection that is based on the assumption that the policy interest rate will not change in the future from its current setting. Private agents must then compare this constant-interest-rate projection to the announced economic objectives in order to back out the actual expected policy rate path. For example, if, at some future date, the published constant-interest-rate inflation projection is higher (lower) 
than the inflation target, then, in general, private agents should infer that the policy rate is likely to increase (decrease). This implicit signaling procedure has been criticized for supplying a circuitous, vague, and potentially confusing expression of the central bank's actual views of the likely path of policy. ${ }^{1}$ Despite these criticisms, a published constant-interest-rate economic projection remains a key component of many central bank communication strategies.

Implicit signaling remains widespread among central banks because nearly all of them are extremely reluctant to directly reveal their views on likely future policy actions. Indeed, one of the strongest central banking taboos is the prohibition against talking publicly about future interest rates (Faust and Leeper 2005). This taboo largely arises from the belief that financial markets would tend to interpret any central bank statements about the likely future path of policy as commitments to future action, as opposed to projections based on existing information and subject to considerable change. Thus, many central banks will at best only give indirect hints or use coded language about policy inclinations in order to retain a plausible deniability in case markets are disappointed as the future unfolds.

Although the expected future path of the policy rate remains a closely guarded secret at most central banks, a few have recently provided some direct signals to the public about their policy intentions. Notably, in 2003, the U.S. Federal Reserve, or more specifically the Federal Open Market Committee (FOMC), started to issue statements commenting on the future path of its policy rate. These verbal forward-looking policy inclinations, including, for example, the famous phrase, "policy accommodation can be removed at a pace that is likely to be measured," have been considered in central banking circles unusually explicit statements about the future path of policy, even though the phrasing is far from unambiguous. A much bolder step than the FOMC's direct verbal signaling has been taken by the central banks of New Zealand and Norway (the RBNZ and the Norges Bank, respectively), which now publish numerical forecasts of the future path of the policy interest rate. These public quantitative policy rate projections represent a dramatic change from the past communication practices of central banks. However, while direct signaling of policy inclinations - whether verbal or quantitative - has been more prevalent in recent years, its future use remains quite contentious and uncertain. Indeed, as a practical matter, Federal Reserve Bank of St. Louis President William Poole (2005a) has stated that "the most important communications issue facing the FOMC currently is whether and how

\footnotetext{
${ }^{1}$ For discussion and critiques of this communication strategy, see Rudebusch and Svensson (1999), Goodhart (2001), Leitemo (2003), Svensson (2005b), Faust and Leeper (2005), and Woodford (2005).
} 
to continue to provide forward guidance on policy decisions."

More broadly, among central bank and academic researchers, there is an ongoing debate about the value of greater transparency and especially the provision of direct signals of the future interest rate path. There may be political benefits obtained from such transparency, such as greater accountability and legitimacy; however, the main argument in favor of directly communicating the central bank's view of the most likely future policy path is an economic one that is based on the benefits of sharing central bank information with private economic agents. As the current Federal Reserve Chairman Ben Bernanke (2004) has suggested, "FOMC communication can help inform the public's expectations of the future course of short-term interest rates, providing the Committee with increased influence over longer-term rates and hence a greater ability to achieve its macroeconomic objectives." This view is supported by research that argues that FOMC statements do affect financial markets and can alter expectations about the future course of policy (e.g., Kohn and Sack 2004, Bernanke, Reinhart, and Sack 2004, and Gürkaynak, Sack, and Swanson 2005a). However, the large research literature on transparency is only a partial buttress for this argument. The theoretical literature has obtained conflicting results on the value of transparency depending on the exact details of the modeling specification. ${ }^{2}$ In addition, this literature has not focused on the issue of the effectiveness of explicit future policy signals for enhancing macroeconomic stabilization. ${ }^{3}$ In the next section, we describe in more detail the real-world direct signaling of policy inclinations by central banks and outline some of the arguments for and against such transparency.

The unresolved debate among central bankers and researchers about the value of the direct signaling of policy intentions provides the key motivation for our formal analysis. In Sections 3 and 4, we examine the macroeconomic effects of direct revelation of a central bank's expectations about the future path of the policy rate in a small theoretical model in which private agents have imperfect information about the determination of monetary policy. In particular, we focus on an issue that has received relatively little attention in the literature, namely, the desirability of central bank transparency about the expected path of policy when the public is uncertain about the central bank's preferences and therefore the future path of policy. We show that publication

\footnotetext{
${ }^{2}$ The literature on central bank transparency is summarized in Geraats (2002), Carpenter (2004), and Woodford (2005). As discussed below, a key dissent on the value of transparency is Morris and Shin (2002, 2005) who argue that, in certain circumstances, greater central bank transparency may lead to less private sector information gathering and reduced welfare.

${ }^{3}$ An important exception is Faust and Leeper (2005) who examine central bank interest rate projections. More generally, Svensson (1997) and Geraats (2005) discuss the value of central bank inflation and output forecasts.
} 
of interest rate projections better aligns the expectations of the public and the central bank in the spirit of Bernanke's quote above. Thus, publishing interest rate projections facilitates the management of expectations and the yield curve. We then show that under reasonable conditions, improving the alignment of expectations also helps the central bank better meet its goals, providing support for full central bank transparency.

\section{The Revelation of Policy Inclinations by Central Banks}

As background for our formal analysis of direct central bank signaling of the likely future path of the policy interest rate, it will be useful to describe briefly some actual instances of such central bank communication and consider the arguments that have been made for and against the provision of these signals.

\subsection{Recent Examples of Direct Policy Signaling by Central Banks}

Some of the most intriguing direct signals of future policy inclinations have been contained in statements issued by the Federal Reserve following FOMC meetings, and it is useful to describe in detail some of this recent history. At times, the FOMC policy statements have provided direct verbal indications of the expected path of policy, which is quite unusual given the Fed's historical secrecy about the setting of the policy rate. Indeed, it was just over a decade ago, in July 1995, that the Fed first even announced a contemporaneous numerical level for the target federal funds rate. ${ }^{4}$ Another example of the Fed's reticence to reveal policy rate information is illustrated in its semiannual Monetary Policy Report. For over two decades, Fed policymakers have been surveyed internally about the economic outlook on a semiannual basis and have been asked to provide macroeconomic forecasts based on their individual views of an "appropriate" (presumably an optimal) future path for the policy interest rate. ${ }^{5}$ The ranges and central tendencies of the resulting inflation, output, and unemployment forecasts are released to the public; however, the underlying conditioning policy paths are not published and, indeed, are not even collected from the survey participants. A similar secrecy applies to forecasts prepared

\footnotetext{
${ }^{4}$ The first policy announcement following an FOMC meeting occurred in February 1994 and only vaguely noted that "the FOMC decided to increase slightly the degree of pressure on reserve positions." In July 1995, the policy statement noted that the decrease in reserve pressures would also be reflected in "a 25 basis point decline in the federal funds rate." Rudebusch (1995) described some of the difficulties in inferring even the ex post level of the federal funds rate target before 1994. Of course, changes in the discount rate, which is an administered interest rate, have always been announced.

5 These economic forecasts are summarized in the Fed's Monetary Policy Report to Congress, which was orginally required by the Full Employment and Balanced Growth Act of 1978.
} 
by the staff of the Federal Reserve Board, which are distinct from the policymakers' own views. These detailed projections are circulated internally before each FOMC meeting in the so-called Greenbook and are made public with a five-year lag. Still, although over one hundred economic series are projected, the underlying staff forecast for the policy rate (the federal funds rate) is not tabulated. ${ }^{6}$

In general, Fed policymakers' views on the future policy path have been so closely guarded that they were only rarely even discussed internally. One exception occurred from 1983 to 1999, when the FOMC voted not only on the current setting of the policy interest rate but also on the expected direction of future changes in the stance of policy over the very near term - strictly speaking, over the "intermeeting period," the approximately six-week interval until the next meeting. ${ }^{7}$ These future policy inclinations were known as the policy "tilt" or "bias." An "asymmetric bias" meant that the FOMC judged that a policy move in one direction was more likely than in the other, while a "symmetric" judgment meant that the next policy move was equally likely to be up or down. Information about the policy bias was contained in the operational instructions or "domestic policy directive" sent to the trading desk at the New York Fed. Before May 1999, each directive was only released to the public after the next FOMC meeting, so, when released, the directive was, strictly speaking, outdated and of limited use to markets. $^{8}$ Following the FOMC meeting in May 1999, as well as after the subsequent five meetings that year, the post-meeting policy statement explicitly announced the expected future direction of policy as contained in the directive. The relevant forward-looking language from these 1999 statements is shown in the first several rows of Table 1. For example, after the October 5, 1999, meeting, the policy statement noted that "the Committee adopted a directive that was biased toward a possible firming of policy going forward."

The Fed's first attempt at directly signaling the direction of future policy in 1999 was, in some sense, a straightforward and logical extension of the earlier transparency about the contemporaneous policy setting that was initiated in July 1995. Essentially, since the FOMC had been voting on both the current policy setting and a future policy inclination, it seemed

\footnotetext{
${ }^{6}$ Similarly, the research staff of the Federal Reserve Bank of San Francisco frequently publish their forecasts for various economic series but never for the federal funds rate.

${ }^{7}$ Especially in the 1990s, the relevant horizon was often interpreted as a longer period, which, as noted below, led to some confusion. Thornton and Wheelock (2000) provide a fascinating history of the policy bias and its interpretation.

${ }^{8}$ The secrecy of the directive was the subject of a famous Freedom of Information complaint that came before the U.S. Supreme Court. As described by Goodfriend (1986, p. 71), one of the reasons given defending the need for the secrecy of the directive was, "The FOMC does not wish to precommit its future policy actions and current disclosure of the directive would tend to precommit the FOMC."
} 
natural to communicate both pieces of information to the public. At the FOMC meeting on July 1, 1998 (based on now-public transcripts), Don Kohn, who was then a Fed research director, noted that an important rationale for releasing the directive stemmed "from a desire at times to warn markets that a change might be forthcoming in order to reduce the odds on an overreaction because of the surprise when policy tightening or easing actually occurred." Any such ability to shape market expectations of future policy by using the policy statement would seem to be quite attractive.

After the fact, however, the Fed policymakers were not pleased with the market reactions to the policy statements in 1999, and there was anguished discussion in FOMC meetings that year about the apparent confused reactions in financial markets to the release of the forwardlooking language. At the start of 2000, given the FOMC's unhappiness with market responses, the direct signals of policy inclinations were replaced by implicit ones, specifically statements about the "balance of risks" to achieving the Fed's economic objectives. The formulaic balance of risks language in the policy statement went as follows, with only one of the three sets of alternative bracketed words to be used depending on the circumstances: "Against the background of its long-run goals of price stability and sustainable economic growth and of the information currently available, the Committee believes that the risks are [balanced with respect to prospects for both goals][weighted mainly toward conditions that may generate heightened inflation pressures][weighted mainly toward conditions that may generate economic weakness] in the foreseeable future." Of course, the three alternative balance of risks options could be roughly mapped into the three earlier policy bias options of higher, unchanged, or lower future rates; however, the looser linkage obtained by avoiding any references to future policy actions appeared important. As Fed Governor Larry Meyer described the motivation for the balance of risks language at the December 21, 1999, FOMC meeting: "The majority [in the FOMC] also wants to change the language to focus on the balance of risks in the forecast in order to detach it from an explicit reference to policy." Indeed, at that meeting, there was a general agreement among the participants at the FOMC meeting to re-establish the taboo against any direct forward-looking signals about policy.

In the event, the implicit balance of risks language was also an imperfect and short-lived alternative. Its tight formulaic corset of a choice between "heightened inflation pressures" and "economic weakness" was not able to capture the Committee's worries in 2003 about a dis- 
inflationary economic slowdown and the possibility of inflation falling too low. Instead, the FOMC again decided that a direct statement about its future policy inclinations could be a useful means to guide market expectations. Therefore, as shown in Table 1, in August 2003, the FOMC introduced the following language into its public statement: "the Committee believes that policy accommodation can be maintained for a considerable period." This was a direct, though not unambiguous, indication that the FOMC anticipated that the policy interest rate could be kept low for some time. The balance of risks language also remained in the statement in various forms, but it was essentially trumped by the direct forward-looking language. This initial direct signal was followed by "the Committee believes that it can be patient in removing its policy accommodation" in January 2004, and by "policy accommodation can be removed at a pace that is likely to be measured" in May 2004, and by "some further policy firming is likely to be needed" in December 2005, and by "further policy firming may be needed" in January 2006. Don Kohn (2005), as a member of the FOMC, described the underlying reasoning behind this return to an explicit signal of future policy:

The unusual situation at that time [in 2003] shifted our assessment of the balance of costs and benefits in favor of a public statement about our expectations for the near-term path of policy. Markets appeared to be anticipating that inflation would pick up soon after the expansion gained traction, and therefore that interest rates would rise fairly steeply. This expectation was contrary to our own outlook. We saw economic slack and rapid productivity growth keeping inflation down for some time. Our expectations about policy also took account of the fact that the level of inflation was already low-lower than it had been for several decades. We thought that our reaction to a strengthening economy would be somewhat different this time than it had been in many past economic expansions and unlike what the markets seemed to anticipate.

Furthermore, unlike in 1999, the direct verbal policy signaling begun by the Fed in 2003 was viewed by many to have been useful in guiding financial markets (as discussed below). However, as noted in the introduction, its continued future use remains open to debate. Indeed, direct interest rate guidance was removed from the policy statement released after the FOMC meeting on June 29, 2006 - the last entry in Table 1. At that meeting, the Fed returned to an indirect indication of future policy inclinations by noting that "some inflation risks remain."

A few other central banks have also provided direct verbal signals about their future policy inclinations. ${ }^{9}$ For example, in 1999, the Bank of Japan lowered its policy interest rate to zero

\footnotetext{
${ }^{9}$ In 2006, the Bank of Canada telegraphed its intentions in policy statements that noted "some modest further increase in the policy interest rate may be required to keep aggregate supply and demand in balance and inflation on target over the medium term."
} 
and announced its intention to maintain the zero rate "until deflationary concerns are dispelled." This verbal signal to the public that the Bank of Japan would maintain a zero policy rate into the future - conditional on continued price deflation - was a key element of what was known as the "zero interest rate policy" and later as "quantitative easing." This signal, which tried to persuade financial market participants to lower their expectations of future short rates and hence lower long rates, was part of an attempt to stimulate the economy and escape from deflation. Just as in the U.S., however, the continued future use of such direct signals appears in doubt. (See Bernanke, Reinhart, and Sack 2004 and Oda and Ueda 2005.)

In contrast to the signals given in the U.S. and Japan, which were verbal and appeared to be transitory responses to special circumstances, two central banks - the RBNZ and the Norges Bank - have been providing quantitative and ongoing guidance on the future policy rate path. ${ }^{10}$ Indeed, the RBNZ has provided numerical policy interest rate projections that reflect the policymaker's views to the public since 1997 (Archer 2005). For example, Figure 1, which is from the March 2006 RBNZ Monetary Policy Statement, contrasts the RBNZ's expected path for future policy over the next two years with the path expected by financial markets. ${ }^{11}$ In this Statement, the Governor of the RBNZ describes the expected policy path as follows: "As long as these inflation risks remain under control, we do not expect to raise interest rates again in this cycle. However given the time that it will take to bring inflation back towards the mid-point of the [inflation] target band, we do not expect to be in a position to ease policy this year. Any earlier easing would require a more rapid reduction in domestic inflation pressures than the substantial slowing already assumed in our projections." All in all, the RBNZ Monetary Policy Statement provides a remarkably clear judgment on the most likely future path of policy.

While the RBNZ has been a pioneer in the publication of quantitative projections of the policy interest rate (and other economic variables), the Norges Bank has recently gone even further, as described in Qvigstad (2005) and Svensson (2006b). Since 2005, the Norges Bank has been providing not only the numerical expected future path of the policy interest rate, but also confidence intervals around this projection and state-contingent alternative scenarios. As shown in Figure 2, which is from the November 2005 Norges Bank Inflation Report, the baseline policy interest rate path rises steadily over the next three years. As described in the report, the

\footnotetext{
${ }^{10}$ The Central Bank of Colombia also published quantitative interest rate forecasts in four inflation reports from December 2003 to September 2004.

${ }^{11}$ The policy rate of the RBNZ is actually an overnight Official Cash Rate, but that is closely linked to the 90-day interest rate, which is displayed.
} 
projections "indicate that the interest rate will increase by about 1 percentage point in the course of next year, which is in line with expectations in the money and foreign exchange market. At the two to three year horizon, we expect a further, gradual rise in the interest rate. Our interest rate projections further out are somewhat higher than forward rates in the financial market." The Norges Bank also provides a probability distribution or fan chart around its baseline interest rate projection, as denoted by the shaded regions in Figure 2. By outlining the range of possible monetary policy responses to unexpected macroeconomic disturbances, these confidence intervals highlight the conditional nature of the baseline projection. The conditionality of the interest rate projection is further reinforced by two specific alternative scenarios that are displayed in Figure 2 and described in the Inflation Report. In one alternative, labeled "Stronger trade shifts," the greater pass-through of low import prices lowers inflation and the policy rate, while in the other, labeled "Higher inflation," a shock boosts inflation and the policy rate.

\subsection{Assessments of Direct Signaling of Policy Inclinations}

The above descriptions of various instances of direct policy rate signaling convey some of the variety of the recent historical experience. The range of practice - from complete silence to explicit quarter-by-quarter numerical guidance - is breathtakingly wide. Such signaling has elicited strong reactions, both pro and con, from central bankers and academic researchers. We will consider two common practical objections to direct signals and then survey some of the research on the effects of transparency.

The first objection is an institutional one. Many have argued that forward-looking policy signals are very difficult, if not impossible, for monetary policymakers to produce; that is, a committee of monetary policymakers may be unable to agree on a likely future path. This is the view of Goodhart (2001), a former member of the Monetary Policy Committee (MPC) of the Bank of England, who notes, "it is hard to see how a committee could ever reach a majority for any particular time path. A great advantage of restricting the choice to what to do now, this month, is that it makes the decision relatively simple, even stark. Given the difficulties involved already in achieving majority agreement in the MPC on this simple decision, the idea

of trying to choose a complete time path by discretionary choice seems entirely fanciful and counterproductive." Blinder (2004) and Mishkin (2004) essentially concur with Goodhart's pessimistic assessment. Of course, as Blinder (1998) earlier bemoaned, it seems quite unsatisfactory 
to ignore the fact that optimal policy in an economy with forward-looking agents will require at least an implicit time profile for future policy. Indeed, Svensson (2005b) has argued that conveying an understanding of the likely future path of the policy rate is crucial, and he suggests obtaining consensus on a quantitative path with a fairly straightforward voting mechanism. In this respect, the successful practical example of the Norges Bank, in which a seven-person Executive Board has been able to agree on and publish a quantitative future policy path, should alleviate some concerns about the impracticality of obtaining agreement on future policy rate signals. ${ }^{12}$ Below, in our formal modeling, we do not address the institutional dynamics of policy committees but simply assume that the monetary authority can formulate a likely future path for the policy rate.

A second objection to direct signaling is that financial market participants will inevitably misinterpret the central bank's signals. ${ }^{13}$ Policymakers often express the fear that financial markets will misconstrue statements of policy inclinations and, in particular, that the markets will interpret them as essentially guarantees of future policy action. ${ }^{14}$ At the FOMC meeting on July 1, 1998, Don Kohn noted that a forward-looking policy announcement "could lock in market expectations and reduce flexibility because it would set up situations in which the market expected some action and the Committee would then have to worry about disappointing those expectations." In the event, of course, as noted above, such misunderstandings did occur. As described in The Wall Street Journal (Schlesinger 2000), "When the Fed started revealing its 'bias' statements in May, financial markets tended to treat the directives as a virtual guarantee of the outcome of subsequent meetings - assuming a 'bias' toward tightening likely meant a rate rise, and that a neutral bias likely meant no rate rise. That wasn't what the Fed intended. With markets ascribing greater clarity to Fed statements than the Fed did, officials at times felt boxed in by extreme market reactions." A similar view of the confusion resulting from the direct signals was expressed in the official postmortem assessment of the 1999 policy statements, titled "Modifications to the FOMC's Disclosure Procedures," (released on January 19, 2000) which

\footnotetext{
12 Alternatively, the diversity of opinion about the future on a policy committee could be informative, and Archer (2005) suggested publishing the "braid" of separate interest rate paths of individual committee members. As noted by Archer (2005), the New Zealand experience is not informative on this issue, as the RBNZ has a single monetary policymaker.

${ }^{13}$ A related objection is that the presence of forward-looking policy signals may change the behavior of financial market participants so that financial markets provide a less useful summary of private information for central banks.

${ }^{14}$ The Governor of the Bank of England (King 2006) recently noted that "trying to give direct hints on the path of interest rates over the next few months risks deceiving financial markets into believing there are definite plans for the next few months when no such plans exist."
} 
noted that the direct forward-looking policy language "caused some unanticipated confusion. It became apparent that the public was uncertain about the interpretation of the language used to characterize possible future developments, about the time period to which it applied, and the extent to which the announced changes in that language represented major shifts in the Committee's assessment. Perhaps partly as a result, the announcement of a directive biased toward tightening seemed to exaggerate the responses of financial markets to subsequent information bearing on the likely course of interest rates and monetary policy."

Of course, part of the confusion in 1999 stemmed from the particular language that was used in the statement. In contrast, the direct verbal policy signals provided by the Fed in 2003 and thereafter have been generally viewed as successful. Kohn (2005), Bernanke (2004), and Woodford (2005), for example, all argue that the language was properly interpreted and that market rates were influenced in the right direction. This interpretation has garnered some support from empirical studies as well. Overall, for example, the incremental steps toward greater openness and transparency that the Fed took throughout the 1990s and early 2000s appear to have had important effects on financial markets. Indeed, as documented by Lange, Sack, and Whitesell (2003) and Swanson (2006), financial markets became much better at forecasting the future path of monetary policy than they were in the 1980s and early 1990s and more certain of their forecast ex ante, as measured by implied volatilities from options. ${ }^{15}$ Other studies that have been more narrowly focused on the specific effects of recent forward-looking Fed policy statements, notably Bernanke, Reinhart, and Sack (2004) and Gürkaynak, Sack, and Swanson (2005a), have supported the notion that these statements have been useful in suggesting to the public a particular course of future action, although as described in Rudebusch (2006), any improvement has been at a horizon of only a couple of months. The experience of the RBNZ, which has given specific numerical policy guidance for over a decade, is generally positive. As discussed by Archer (2005), financial markets in New Zealand have reacted favorably to the central bank's interest rate forecasts, and understood their conditionality. Although the Norges Bank has only a very brief track record of interest rate projections, the explicit confidence bands provided should reinforce forecast conditionality, and so far, its experience has been favorable.

Of course, the counterfactuals in these cases cannot be observed, so it is difficult to assess

\footnotetext{
${ }^{15}$ Of course, this greater certainty about future rates may be precisely the worry of those opposing direct guidance on interest rates, namely, that providing information about the first moment of future interest ratesthe expected path - will distort the second moment of future rates, reducing the implied volatility or dispersion of expected future rates in an unwarranted fashion.
} 
definitely the effectiveness of the recent direct interest rate communication. Indeed, some have judged the recent U.S. episode far less favorably. As noted in Business Week (Miller 2005): "But what started out as a well-meaning attempt to give investors a clear sense of where monetary policy was headed has degenerated into a muddled message that has sown confusion in financial markets and helped fan fears of higher inflation among investors. That has raised questions inside and outside the Fed about whether the central bank's extraordinary strategy of mollycoddling the markets has done more harm than good." And the president of the European Central Bank (ECB), Jean-Claude Trichet (2006), made it clear that the ECB would not be sending similar direct signals about the likely path of its policy interest rate. ${ }^{16}$

Even among those who judged the Fed's direct signaling to have been useful, many considered it a one-time solution for a transitory deflationary risk. Notably, the signaling could be considered a particular example of the strategy of stimulating the economy discussed by Reifschneider and Williams (2000) and Eggertsson and Woodford (2003), which provides assurances when the current policy rate is close to or at its lower bound that future rates will also be kept low. Indeed, as noted above, it appears unlikely that the Fed will employ an ongoing strategy of direct signaling. For example, in the U.S., the minutes of the FOMC meeting of November 10, 2004, stated, "A few members felt that, because of greater uncertainties, it might become appropriate eventually to move away from the recent practice of providing guidance about the likely future path of policy, while others emphasized the desirability of continuing to be as informative as possible about the Committee's perceived outlook." And, as noted above, direct signals were discontinued in the June 2006 policy statement. ${ }^{17}$

For some, given the sophistication of the financial system, it is perhaps easy to dismiss at an abstract level concerns about the inevitable breakdown of communication between central banks and markets. However, there is still much unknown about the precise relationship between the

\footnotetext{
${ }^{16}$ Trichet noted that "the ECB does not embark on a particular multi-monthly pre-commitment on interest rates or on the path of future policy interest rates. As the Governing Council has decided to regularly consider the most up-to-date information, such an unconditional commitment would limit the ability of the Governing Council to react to changes in the economic situation and therefore hamper our credibility and our capacity to preserve the solid anchoring of inflation expectations. This is, in particular, the reason why we refused to promise to maintain interest rates at 2 percent for a "considerable period of time."'

17 Poole (2005b) appears to express the view of at least a few FOMC members when he notes that "most of the time the FOMC cannot provide accurate information to the market as to the probable course of the target fed funds rate, in terms of a specific path measured in basis points. The future path will be conditional on future information that cannot itself be predicted. Attempts to provide specific forward-looking guidance will prove inaccurate and even misleading to the market. Moreover, the Fed could create a credibility problem for itself if forward guidance is too specific. If the market acts on the guidance, and the Fed subsequently responds to new information in a way that departs from the guidance, then the market will naturally feel that it has been misled. But if the Fed fails to respond to new information that seems to demand a response, in the interest of doing what it said it was going to do, then failure to respond may also damage credibility."
} 
revelation of information and market pricing, and this black box has long worried central bankers (Goodfriend 1986). Perhaps the most subtle rendering by a policymaker of the difficulties inherent in communicating with financial markets is provided by Kohn (2005):

In fact, economists do not fully understand how markets incorporate information. Herding behavior, information cascades, multiple equilibria, and the amount of investment in financial research all pose puzzles about markets and information. The situation is complicated still more when an important participant is seen as having superior information owing to its investment in research or its understanding of its own behavior. In such circumstances, certain types of central bank talk might actually impinge on welfare-enhancing market pricing by being misunderstood and receiving too much weight relative to private judgments.

Some of the research underlying this apprehension about transparency is by Morris and Shin (2002), who provided a simple theoretical model in which the public revelation of policy information can be bad for social welfare. This work has been widely cited and followed by a vigorous debate introducing new theoretical modifications. For example, Svensson (2006a) argues that the Morris and Shin result has been widely misinterpreted and that their anti-transparency result is only obtained for a small set of unlikely parameter values, while various authors, including Roca (2005) and Hellwig (2005), show that transparency can increase welfare in more general models. Indeed, as is apparent in surveys by Geraats (2002), Carpenter (2004), and Woodford (2005), many conclusions about the value of transparency appear to hinge on the exact specification of the theoretical models. However, with just a few exceptions, the literature has not actually examined the effects of the release of forward-looking policy information for macroeconomic dynamics and stabilization. It is this is line of reasoning that we pursue in the next two sections.

\section{A Framework for Analyzing Central Bank Interest Rate Projections}

In this section and the next, we analyze how publishing central bank interest rate projections can affect private expectations and macroeconomic performance in a simple model of the economy. In this section, we describe our framework, which is a standard New Keynesian structure modified to allow for asymmetric information sets for private agents and the central bank. In particular, in our model, as described in detail in the next section, the central bank may have an informational advantage over the public that reflects its better information regarding its policy intentions. At the outset, note that we abstract from two issues that have been widely discussed in the past 
literature on central bank transparency. First, we assume that the central bank is able to commit to future policy actions and therefore does not face a Barro-Gordon time inconsistency problem. Second, we assume that the central bank's provision of information does not affect a private agent's collection or use of idiosyncratic information; thus, we ignore the strategic complementarity highlighted in Morris and Shin (2002).

\subsection{A Model of Interest Rates, Output, and Inflation}

For our analysis, we use a standard log-linearized New Keynesian model (see Woodford 2003 for further discussion). The output gap, $y_{t}$, is determined by a forward-looking "IS curve" given by the intertemporal saving decision:

$$
y_{t}=-\left(i_{t}-\mathrm{E}_{t} \pi_{t+1}-r_{t}^{*}\right)+\mathrm{E}_{t} y_{t+1},
$$

where $i_{t}$ is the nominal interest rate, $\pi_{t}$ is the inflation rate, $r_{t}^{*}$ is the natural rate of interest (which is assumed to follow a known stationary process), and $\mathrm{E}_{t}$ denotes mathematical expectations conditional on the available time $t$ information set. (Throughout our analysis, we abstract from intercepts.) We have implicitly assumed log preferences so that the coefficient on the interest rate is unity. Solving this equation forward $T$-1 periods, we can express the output gap in terms of the expected short-term real interest rate gaps over the next $T$ periods and the output gap $T$ periods in the future:

$$
y_{t}=-\mathrm{E}_{t} \sum_{j=0}^{T-1}\left(i_{t+j}-\pi_{t+j+1}-r_{t+j}^{*}\right)+\mathrm{E}_{t} y_{t+T} .
$$

This version of the IS curve illustrates a basic insight of modern macroeconomic theory: monetary policy affects output through the expected future path of real interest rates. Generalizations of this model that incorporate a richer description of consumption, investment, and other components of output leave this basic insight intact (see Woodford 2003 and Fuhrer and Rudebusch 2004 for discussion).

It is useful to reformulate this condition in terms of bond yields. Denote the ex ante real $T$ period bond rate by $R_{T, t}$, which, abstracting from a term premium, equals the expected average real interest rate over the next $T$ periods:

$$
R_{T, t} \equiv-\mathrm{E}_{t} \frac{1}{T} \sum_{j=0}^{T-1}\left(i_{t+j}-\pi_{t+1+j}\right) .
$$


Let $R_{T, t}^{*}$ denote the expected average natural rate of interest over the next $T$ periods :

$$
R_{T, t}^{*} \equiv \mathrm{E}_{t} \frac{1}{T} \sum_{j=0}^{T-1} r_{t+j}^{*}
$$

Given these definitions, the IS curve can be represented by the following simple equation relating the output gap to the real bond rate gap, which is the difference between the real bond rate and the corresponding natural rate, plus the output gap expected T periods in the future (which, for sufficiently large values of $\mathrm{T}$ is approximately zero):

$$
y_{t}=-T\left(R_{T, t}-R_{T, t}^{*}\right)+\mathrm{E}_{t} y_{t+T}
$$

This formulation makes evident the central role of long-term real interest rates for the conduct of monetary policy (see McGough, Rudebusch, and Williams 2005).

The inflation rate, $\pi_{t}$, is given by the New Keynesian Phillips curve of the form:

$$
\pi_{t}=\beta \mathrm{E}_{t} \pi_{t+1}+\kappa\left(y_{t}+u_{t}\right)
$$

where $u_{t}$ is a distortionary stationary shock to marginal cost, $\beta$ is the rate of time preference, and $\kappa$ measures the sensitivity of inflation to the output gap. Solving this equation forward yields the following equation for inflation in terms of expected real bond rates:

$$
\pi_{t}=-\kappa \mathrm{E}_{t} \sum_{j=0}^{\infty} \beta^{j}\left(R_{T, t+j}-R_{T, t+j}^{*}+y_{t+T}-u_{t+j}\right) .
$$

As in the case of the output gap equation, this reformulation of the Phillips curve highlights the central role of expected real bond rate gaps in determining current inflation. It is clear from this representation that private agents, and by implication monetary policymakers who strive to ensure macroeconomic stabilization, are interested in the whole future path of the short-term policy interest rate.

For our analysis below, we assume $\kappa=0.15$ and $\beta=1$. The value of $\kappa$ is consistent with Calvo price setting with one-quarter of all prices reoptimized each quarter, log utility from consumption, and a 0.8 elasticity of disutility from work. ${ }^{18}$ We assume that the variance of the markup shocks equals unity; shocks to the natural rate of interest play no part in our analysis below. Our results are not qualitatively sensitive to these parameter assumptions.

\footnotetext{
${ }^{18}$ We assume $\beta=1$, so monetary policies can be easily evaluted in terms of unconditional variances.
} 


\subsection{Monetary Policy}

As is standard in the literature, we assume that the central bank's objective is to minimize the weighted sum of the unconditional variance of the inflation gap, which is the difference between the inflation rate and a time-varying target inflation rate $\pi_{t}^{*}$, and the unconditional variance of the output gap. Specifically, the central bank loss, $\mathcal{L}$, is given by:

$$
\mathcal{L}=\operatorname{VAR}\left(\pi_{t}-\pi_{t}^{*}\right)+\lambda \operatorname{VAR}\left(y_{t}\right),
$$

where $\operatorname{VAR}(x)$ denotes the unconditional variance of a variable $x$ and $\lambda$ is the relative weight on output gap variability.

We allow for modest variation over time in the medium-term inflation rate that the central bank attempts to achieve. Specifically, we assume that the inflation target is a mean zero autoregressive process, subject to stochastic shocks:

$$
\pi_{t}^{*}=\delta \pi_{t-1}^{*}+v_{t}, \quad \delta \in(0,1), \quad v_{t} \sim N\left(0, \sigma_{v}^{2}\right)
$$

where the inflation target innovation, $v_{t}$, is assumed to be an i.i.d. normally-distributed random variable. Note that the unconditional, or long-run, inflation target is assumed to be constant. We assume that $\pi_{t}^{*}$ is persistent, with $\delta=0.9$, but that its conditional variance is quite small, with $\sigma_{v}^{2}=0.01$. Persistent target shocks can be justified by time variation in the factors that influence the optimal choice of the inflation rate, including distortions to the economy, bias in inflation measures, and structural changes that affect the magnitude of the problems associated with the zero lower bound on interest rates. In addition, the optimal strategy in the vicinity of the lower bound is to implicitly target a higher rate of inflation than usual for a number of years, as discussed in Reifschneider and Williams (2000) and Eggertson and Woodford (2003), providing justification for time variation in the medium-run inflation objective. ${ }^{19}$ Note that the assumed implied unconditional standard deviation of the inflation target is only about 0.2 percentage point, which is plausibly modest. Indeed, much related recent macro-finance research finds that the inflation target embedded in bond yields does move significantly and persistently over time (e.g., Kozicki and Tinsley 2001, Rudebusch and Wu 2004, 2006, Gürkaynak, Sack, and Swanson 2005b, and Hördahl, Tristani, and Vestin 2006). ${ }^{20}$ In any case, the resulting

\footnotetext{
${ }^{19}$ For example, one could interpret the recent heightened concerns about the possibility of deflationary stagnation in the United States as an episode of implicitly targeting a somewhat higher rate of inflation than usual for a few years owing to concerns about the zero lower bound on interest rates.

20 More generally, in the United States, and in many other countries, there is considerable empirical evidence
} 
unconditional variation fits well inside the explicit inflation target ranges announced by many central banks, which are typically a percentage point in width.

As discussed in Woodford (2003), in this model optimal monetary policy under commitment with complete information is implicitly described by the condition:

$$
\pi_{t}=\pi_{t}^{*}-\frac{\lambda}{\kappa}\left(y_{t}-y_{t-1}\right)
$$

In the following, we append a transitory policy shock, $w_{t}$, to this optimality condition, so that monetary policy is set according to:

$$
\pi_{t}=\pi_{t}^{*}+w_{t}-\frac{\lambda}{\kappa}\left(y_{t}-y_{t-1}\right)
$$

where $w_{t}$ is assumed to be an i.i.d. normally-distributed random variables with variance $\sigma_{w}^{2}=1$. Throughout the following, we assume that policy is set according to this equation and is not recalibrated depending on the information assumptions that we make. We view the policy shocks as representing the central bank's response to transitory factors outside the model. Indeed, as stressed by Svensson (2005a, b), good monetary policy in practice involves a vast amount of subtle knowledge and judgment. In part, such information may reflect policymakers' assessments about asymmetric risks to the outlook that are not directly connected to the mean forecast for inflation and output. For example, these asymmetric risks may reflect fears about fallout from financial instability, and the Fed has responded a number of times to threats to the financial system: in 1987, following the stock market crash, in 1998, when international financial markets threatened to freeze up, and in 2001, following the terrorist attacks on September 11. Finally, it should be stressed that in real time the policymaker may not have a clear read on the data and does not know the best way to minimize the loss function.

Although the policy equation is written in an implicit form in terms of the inflation gap and the change in output, it can be equivalently represented by an explicit interest rate reaction function where the policy instrument, the short-term interest rate, is determined by variables in the system. In such a formulation, the time-varying inflation target, $\pi_{t}^{*}$, and the policy shock, $w_{t}$, represent deviations by the central bank from its policy reaction function, similar to the residuals of an estimated monetary policy rule (as in Svensson 2003 and Rudebusch 2002, 2005).

that persistent shocks to the inflation target have occurred, as exemplified by the disinflations of the early 1980 s and again in the early 1990s, which suggest a gradual ratcheting down of the inflation target over time. See, for example, Bomfim and Rudebusch (2000), Erceg and Levin (2003), and Cogley and Sbordone (2005). 


\section{The Macroeconomic Effects of Publishing Interest Rate Projections}

In this section, we use the theoretical framework outlined above to analyze how publishing central bank interest rate projections affects macroeconomic behavior and the central bank calculation of loss. A crucial aspect of our analysis is the structure of information: what the public knows and doesn't know. Because the focus of this paper is on the effects of publishing interest rate projections, in the following we focus on the effects of incomplete knowledge on the part of the public regarding the future path of policy that is ultimately due to uncertainty about the future actions of the central bank. We abstract from information asymmetries regarding the state of the economy, a topic analyzed in a recent paper by Walsh (2005). In particular, we assume that the public and the central bank have identical and complete information about the parameters describing the model economy and both observe the current shocks to the natural rate of interest and the shock to marginal costs, $r_{t}^{*}$ and $u_{t}$, respectively. ${ }^{21}$ That is, the public and the central bank are both assumed to know the structure and parameters of the equations describing output, inflation, and the inflation target, and the functional form of the equation describing monetary policy.

We consider two illustrative examples where the public is imperfectly informed regarding future policy actions and is uncertain how the central bank will respond in the future to economic conditions. First, we analyze the case, which we refer to as "policy rule uncertainty," in which the public does not know the parameters of the policy rule. In this case, private agents must estimate a policy rule using information from both past central bank actions and information contained in published interest rate projections. The publication of central bank interest rate projections may facilitate the public's understanding of the policy rule and so improve their predictions of future policy actions. In the second case, we examine an economy where the public has imperfect knowledge of the central bank's medium-run inflation target, $\pi_{t}^{*}$, which we refer to as "inflation target uncertainty." The public is assumed to infer the medium-run inflation target from information contained in past policy actions and from central bank interest rate projections. The publication of interest rate projections may improve the public's estimate

\footnotetext{
21 This assumption seems appropriate for analyzing inflation targeting central banks, the majority of which provide detailed information regarding their views on the economic outlook, conditional on some stipulated path of policy (e.g., constant nominal rate or market expectations). For non-inflation targeting central banks, communication of interest rate projections likely conveys useful information both about the central bank's views on the economy and about the policy response to the outlook. See Geraats (2005) for a discussion and references to the literature on the effects of transparency when the central bank has asymmetric information regarding the economic outlook.
} 
of the medium-run inflation target and thereby improve the public's ability to forecast future policy actions.

\subsection{Policy Rule Uncertainty}

We first analyze an economy where the public knows the central bank's inflation target but is uncertain about the parameterization of the central bank's policy rule. In this case, the public forms its expectations about future policy and the economy using an estimated policy rule. $^{22}$ The assumption that the public is uncertain about the central bank's reaction functions seems realistic in light of the ongoing debate about the specification and parameters of the FOMC's reaction function. More generally, given the limited available data from consistent policy regimes, uncertainty about central bank reaction functions appears to be a pervasive feature of the economic landscape.

One could imagine a central bank publishing its policy rule and eliminating this type of uncertainty. Indeed, Svensson (2005b) has argued that the central bank should publish its objective function and model and thereby provide the public with all the information it needs to form expectations of future policy actions. However, we view a central bank's knowledge and understanding of its own preferences, and by implication its policy strategy, as far too complex and inchoate ever to be explicitly expressed to the public or, indeed, even written down within the halls of the central bank. Not surprisingly, no central bank has yet put Svensson's proposal into practice. Still, based on the experiences discussed earlier in this paper, we do think that the central bank can provide a potentially useful signal to the private sector of its plans for the future setting of the policy rate.

In the simplified model that we are using, there is only a single free parameter in the policy rule to be estimated: the coefficient in front of the change in the output gap, $\lambda / \kappa$. Assuming (as we do) that the public knows the value of $\kappa$, uncertainty about the parameters of the monetary policy rule is equivalent to uncertainty about the central bank's preferences, in particular, the penalty on output gap variability. We assume that private agents know the general formulation of the policy rule and know the true inflation target, so that their estimation problem is far simpler than that faced by the public in reality. In this way, our analysis likely understates the effects of publishing interest rate projections on public expectations and macroeconomic

\footnotetext{
${ }^{22}$ A similar problem was studied by Orphanides and Williams (2005), but they did not consider the value of interest rate projections in improving the public's estimates of the policy rule.
} 
performance. Nonetheless, the analysis of this simple problem nicely illustrates the qualitative effects of providing interest rate projections when the public is uncertain how the central bank will react to economic conditions.

Of course, in theory, if a policy regime were fixed for all time, agents would gradually accumulate precise information regarding the policy rule from observed policy actions and the uncertainty regarding the central bank's preferences would vanish. In practice, however, agents must form expectations having gathered only a finite set of observations of any given policy regime. One could explicitly endogenize the choice of the data sample used in policy rule estimation by allowing for time variation in the value of $\lambda$, but that would introduce a nonlinearity into the model and significantly complicate the analysis. Instead, for the present purpose, we assume that the policy regime is fixed and simply posit an environment where agents use only $n$ observations in estimating the monetary policy reaction function. We consider two illustrative cases: in one, agents use the past 40 observations (10 years of data) in estimating the policy rule; in the second, agents use 80 observations (20 years of data).

We assume the central bank can choose to augment the public's information regarding the monetary policy rule through communication of its future policy intentions. Specifically, we assume that each period, the central bank can provide a signal, denoted $i_{t+1 \mid t}^{P}$, of its own internal projection of the next period's interest rate setting, denoted $\mathrm{E}_{t}\left[i_{t+1} \mid C B\right]$, where the conditioning information set is clearly denoted as the central bank's. (In the literature, these are often termed "unconditional" forecasts.) $)^{23}$

As discussed in Section 2, central bank communication of interest rate projections is often verbal and imprecise in practice. Even if the central bank provides a numerical interest rate projection, the manner in which it is constructed, say by taking a median vote, may create a wedge between the published projection and the true expected path for interest rates. Therefore, in our analysis, we allow for transmission noise in conveying the interest rate projection to the public. This noise reflects the fact that the central bank may not be able to, or may not choose to, send a perfectly clear signal of its expectation of future policy. In particular, we assume that

\footnotetext{
${ }^{23}$ Note that in the simple model that we consider, the central bank could provide "unconditional" projections of inflation or the output gap, meaning projections consistent with the projected future path of interest rates, and the analysis and results would be the same as in the case of interest rate projections. This equivalency obtains because all of these projections are linear combinations of the same state variables. This contrasts with the case of central bank publication of forecasts of inflation and output conditional on an arbitrary assumed path of policy with no explicit guidance on policy, as is typically done in many central banks. These conditional forecasts yield no useful information regarding the nature of the shocks to the public in our model.
} 
the central bank signal of its interest rate projection is given by:

$$
i_{t+1 \mid t}^{P}=\mathrm{E}_{t}\left[i_{t+1} \mid C B\right]+z_{t}, \quad z_{t} \sim N\left(0, \sigma_{z}^{2}\right)
$$

where the transmission noise, $z_{t}$, is assumed to be an i.i.d. normally distributed random variable with variance $\sigma_{z}^{2}$. The limiting case of $\sigma_{z}=\infty$ corresponds to the central bank providing no useful information to the public regarding the future course of policy. The opposite limiting case of $\sigma_{z}=0$ corresponds to the central bank perfectly communicating to the public its expectation of the interest rate path and thereby its policy rule. For intermediate cases, we interpret a highly noisy signal, say $\sigma_{z}=1$, as corresponding to a central bank providing only qualitative hints about the possible direction of future policy. A modestly noisy signal, say $\sigma_{z}=0.1$, suggests a central bank providing fairly detailed, numerical information about its expectations of the future path of policy.

Note that for analytical convenience, we assume that all the information regarding the future course of policy is contained in the central bank's one-step-ahead projection of the interest rate. In practice, a central bank is likely to communicate a forecast that covers several periods. In our model, there is no additional information contained in the two-step-ahead forecast that is not already contained in the one-step-ahead forecast. More generally though, we view providing a multi-period forecast as a way to reduce the transmission noise relative to a one-step-ahead forecast, so it can be analyzed in this framework as a reduction in the degree of transmission noise.

Given the past history of central bank signals and actions, private agents estimate the value of $\lambda$ on the basis of the policy equation. In particular, at the end of each period, agents run two regressions using the most recent $n$ observations of data. The first is a regression of the observed inflation gap on the observed change in the output gap. Because we assume the inflation target is known, no intercept or other term is included in the regression. Note that the innovation to this equation is the policy shock, $w_{t}$. Because this equation involves endogenous variables on both sides, estimation is done using instrumental variables, where the lagged output gap is the instrument. The second is a regression of the expected one-period-ahead inflation gap on the expected one-period-ahead change in the output gap consistent with the published central bank interest rate projection. Estimation of this equation is likewise done using instrumental variables. Note that the innovation in this case is the central bank transmission noise, $z_{t}$. In both cases, we impose the restriction that the estimated coefficient be positive, consistent with the restriction 
that the penalty on output gap variability be non-negative. For symmetry and to avoid an upward bias in the estimates, we also impose the restriction that the estimated coefficient be no larger than twice the true value. Given the assumption that $\lambda=1$, the estimates are constrained to lie between 0 and 2 , inclusive.

Estimation of these two equations yields two point estimates of $\lambda$ and estimates of the variances of the residuals in the two equations. We assume that agents then form an estimate $\hat{\lambda}_{t}$ by taking a weighted average of the two point estimates, with the weights equaling the inverse of the respective standard deviations of the regression residuals. In this way, agents take into account the relative amounts of noise observed from the two sources of information regarding the monetary policy rule. ${ }^{24}$ In the following period, agents compute expectations of future variables conditional on $\hat{\lambda}_{t}$. Then, given the realized values of the innovations, the values of all endogenous variables are computed. The process is then continued, with agents reestimating the policy rule equations at the end of each period. ${ }^{25}$ We compute the statistics of interest for these experiments using model stochastic simulations. We run each simulation 41,000 periods and drop the first 1,000 periods to minimize the effects of initial conditions.

Central bank publication of interest rate projections improves the public's understanding of the central bank's policy rule. The solid line of Figure 3 shows the root mean squared error (RMSE) of $\hat{\lambda}_{t}$ (relative to the true value of $\lambda=1$ ) over the simulations for various degrees of transmission noise, as measured by $\sigma_{z}$. As noted above, the solid line assumes that agents estimate the policy rule using only 40 periods of data, but still the average estimation errors for $\hat{\lambda}_{t}$ are reasonably modest. As seen in the figure, clear communication of interest rate projections facilitates the public's ability to estimate the policy rule. With zero transmission noise, the public's estimate of the policy rule equals the true policy rule at all times. But, as the degree of transmission noise rises, the accuracy of the public's estimates of the policy rule diminishes, and the public's ability to predict future policy actions also deteriorates.

Publication of interest rate projections is potentially useful at aligning private and central bank expectations even if the public has a relatively long history of observations of policy actions. The dashed line in Figure 3 shows the RMSE of $\hat{\lambda}_{t}$ assuming that agents use 80 observations in

\footnotetext{
${ }^{24}$ This method of combining estimates performs very well in terms of the resulting efficiency of the estimates in the model simulations. An alternative approach of having agents apply maximum likelihood would likely yield similar results, but at a much greater computational cost.

25 Technically, each period, we compute the rational expectations equilibrium consistent with the public's estimate of $\lambda$. We then compute residuals to the policy rule equation and to the equation describing the policy projection that make the setting of policy and the expectation of policy consistent with the true value of $\lambda$ and the realized values of $w_{t}$ and $z_{t}$.
} 
estimating the policy rule. ${ }^{26}$ Not surprisingly, the effect of publishing interest rate projections (for a given transmission noise) is smaller when the public has a longer history of policy actions on which to base their policy rule estimates. Nevertheless, even with 20 years of data, publication of interest rate projections can have a potentially significant effect on the ability of the public to predict future policy actions.

This alignment of the public's and the central bank's expectations of future policy actions reduces the magnitude of fluctuations in output and the inflation gap and therefore on the central bank loss. The solid line in Figure 4 shows the central bank loss for various degrees of central bank transmission noise, $\sigma_{z}$, when $n=40$. For comparison, the loss assuming that the central bank does not publish interest rate projections is about 1.03. The central bank loss is minimized when the transmission noise is zero and rises as $\sigma_{z}$ increases. Even a noisy central bank signal of policy intentions yields a noticeable improvement in macroeconomic performance over that which would occur absent central bank publication of interest rate projections.

The benefits of central bank communication of interest rate projections are greatest when the public has relatively little data. The dashed line shows the corresponding results for $n=$ 80. The benefits of communicating policy intentions are only about one-half as large as when $n=40$. Of course, in the limit as the sample size increases to infinity, central bank interest rate projections would be superfluous because the public would know the exact policy rule based on past observations of policy actions.

These results show that when the public is uncertain about how the central bank will respond to economic conditions, publishing interest rate projections can help align private and public expectations of future policy actions and thereby improve macroeconomic performance. This finding confirms that of Orphanides and Williams (2004), who, using a simple stylized model, find that the central bank loss is lower when the public knows the monetary policy rule than if they have to estimate the policy rule based on limited data.

\footnotetext{
${ }^{26}$ The doubling of the number of observations would, all else equal, lead to a reduction in the RMSE by a factor of $\sqrt{2}$. This is indeed approximately true for the results reported in Figure 3 when $\sigma_{z}$ is $1 / 2$ or smaller. However, the restriction that $\hat{\lambda}_{t}$ be between 0 and 2 reduces its RMSE, and this effect is larger when the sample size is small and when the magnitude of transmission noise is large. As a result, for values of $\sigma_{z}$ above $1 / 2$, the RMSE curve for $n=40$ lies below what would be expected based on the difference in sample sizes.
} 


\subsection{Inflation Target Uncertainty}

The case of policy rule uncertainty provides a strong case for central bank transparency and the potential value of publishing central bank interest rate projections. We now consider the case where the public is uncertain regarding the true value of the medium-run inflation target. ${ }^{27}$ The case of inflation target uncertainty is of particular interest for two reasons. First, this case is of interest on its own merit. As discussed in Woodford (2005) and Williams (2006), a central bank constrained by the zero lower bound on interest rates will want to engineer above-trend inflation for a time; but, if the public has little experience with policy constrained by the zero bound, private agents may not understand the central bank's intentions. Second, this case is well suited for analyzing the issue of the effects of interest rate projections if the public inefficiently uses the information contained in interest rate projections.

In analyzing inflation target uncertainty, we assume as before that the public and the central bank have complete information regarding the other aspects of the economy. We also continue to assume that the central bank communicates in terms of a noisy one-period-ahead internal forecast of the interest rate. And, to keep the analysis as simple as possible, we now assume that the public knows the central bank's preference parameter $\lambda$. Under these assumptions, the public faces a standard signal extraction problem in order to try to disentangle the realizations of the inflation target and the policy shock. One way to interpret the solution to this problem is to consider what private agents will determine as the most likely value of the true inflation target from realized policy actions and published central bank interest rate projections. We assume that the central bank, but not the public, knows the realized values of the two policy-related innovations, $v_{t}$ and $w_{t}$. The public observes the current interest rate, from which it can infer the sum, $\pi_{t}^{*}+w_{t}$, but it cannot disentangle the current level of the inflation target and the realization of the policy shock $w_{t}$. Likewise, from the published interest rate projection, the public can infer the sum, $\delta \pi_{t}^{*}+\psi z_{t}$, where $\psi$ measures the relationship between the inflation target and the interest rate implied by the monetary policy rule, but it cannot disentangle the expected level of the inflation target and the realization of the transmission noise shock, $z_{t}$.

Given the assumptions of independent Gaussian disturbances, the resulting optimal filter estimate of the inflation target at time $t$, based on information available in period $t$, denoted by

\footnotetext{
${ }^{27}$ For further discussion of target shocks in the context of public uncertainty of future policy actions, see Faust and Svensson (2001) and Geraats (2005).
} 
$\hat{\pi}_{t}^{*}$, is given by

$$
\hat{\pi}_{t}^{*}=\delta \hat{\pi}_{t-1}^{*}+\gamma\left(\pi_{t}^{*}+w_{t}-\delta \hat{\pi}_{t-1}^{*}\right)+\theta\left(\delta \pi_{t}^{*}+\psi z_{t}-\delta \hat{\pi}_{t-1}^{*}\right)
$$

where the parameter $\gamma \in[0,1]$ is the gain associated with the revelation of the policy action and the parameter $\theta \in[0,1]$ is the gain associated with the central bank's projection of the interest rate in the next period. We initially assume that agents know the true values of the variances of the different shocks and filter the data optimally. Given that the shocks $w_{t}$ and $z_{t}$ are independent, the signal-to-noise ratio of the combined two signals, denoted $\phi$, is given by:

$$
\phi \equiv \frac{\sigma_{v}^{2}}{\sigma_{w}^{2}}+\frac{\delta^{2}}{\psi^{2}} \frac{\sigma_{v}^{2}}{\sigma_{z}^{2}} .
$$

The optimal steady-state filter gains, $\gamma^{*}$ and $\theta^{*}$, are given by the following two equations:

$$
\begin{gathered}
\gamma^{*}+\theta^{*}=1-\frac{2}{2-\left(1-\delta^{2}-\phi\right)^{2}+\sqrt{\left(1-\delta^{2}-\phi\right)^{2}+4 \phi}}, \\
\gamma^{*}=\frac{\gamma^{*}+\theta^{*}}{\phi} \frac{\sigma_{v}^{2}}{\sigma_{w}^{2}} .
\end{gathered}
$$

The first equation is the standard formula for a problem of two independent Gaussian latent variables, where one follows an $\mathrm{AR}(1)$ and the other is serially uncorrelated (see Harvey 1989). The second equation parses the sum of the two gains according to the relative signal-to-noise ratios of the two processes.

Private agents form expectations of future variables based on their resulting estimate of the inflation target, and output, inflation, and interest rates are determined conditional on the public's estimate of the inflation target. Figure 5 displays the optimal filter gains associated with the policy action, $\gamma^{*}$, and with the interest rate projection, $\theta^{*}$, respectively. Not surprisingly, if the central bank signal of its policy intentions is highly noisy, the public mostly ignores the signal and bases its beliefs primarily on policy actions. As the clarity of the central bank projections improves, the public places greater weight on those projections and less weight on the current policy setting. As the signal-to-noise goes to zero, the public optimally responds only to published interest rate projections and not at all to policy actions. ${ }^{28}$

\footnotetext{
${ }^{28}$ As in the case of policy rule uncertainty, if the central bank perfectly communicated its expectation of the interest rate in the next period $\left(\sigma_{z}=0\right)$, this information would be sufficient for the public to completely ascertain the inflation target. Additional information from the central bank about its projection of interest rates two, three, or more periods in the future would be superfluous. However, as mentioned above, we interpret our analysis in terms of providing signals on the projected path of interest rates over a few years.
} 
The public's inaccurate assessments of the medium-run inflation target create persistent discrepancies between the public's estimate of the target and the target's true value which distort the paths of inflation and the output gap away from those desired by the central bank. Imperfect public information about the inflation target affects the responses to shocks to the policy rule and the inflation target. Given the relatively small variance assumed for the inflation target shocks, persistent shifts in the inflation target are relatively "rare," so the public's view of the inflation target is not very sensitive to a surprising policy action. Indeed, in the absence of interest rate projections, the optimal gain parameter for policy actions, $\gamma$, equals 0.043 , indicating that the public's estimate of the inflation target initially would rise only by 4.3 basis points in the period of a one percentage point shock to the actual target. The public's misperception of the inflation target gradually shrinks over time, both because the target itself is returning to baseline and the public's estimate is catching up with the target. With imperfect information, following a positive shock to the inflation target, the public wrongly ascribes too much central bank behavior to the transitory policy shock, so output rises more and inflation rises less than if the public knew about the shift in the inflation target. The excessive rise in the output gap continues and eventually causes the inflation rate to persistently overshoot the true target. As a result, the loss associated with a shock to the inflation target is greater when the central bank does not effectively communicate its intentions.

Although central bank communication helps improve the public's understanding of the medium-run inflation target, it also potentially introduces public expectational errors owing to central bank transmission noise that otherwise would be absent. The noise in the interest rate signal distorts the public's expectations of future policy and is a source of aggregate variability. The magnitude of these misperceptions depends on both the variance of the transmission noise shocks and the filter gain applied by the public to central bank communication. We account for this "cost" of noisy transmissions in our calculation of the effects of publishing interest rate projections.

Publishing interest rate projections improves the public's ability to discern the true mediumrun inflation target, leading to better macroeconomic outcomes. The solid line in Figure 6 shows the central bank loss as a function of the degree of central bank communication transmission noise, assuming that the public uses the optimal filter described above. An increase in transparency achieves a better alignment of public expectations of future policy with those of the 
central bank. The improved management of expectations of future rates and thereby long-term bond rates pushes the economy's responses to the inflation target and policy shocks closer to the complete transparency benchmark. On net, the benefits of improved understanding of the inflation target outweigh the costs of extra noise in the system resulting from central bank communication noise, and the loss monotonically decreases as the quality of the signal about the central bank's interest rate projection improves. These results are robust to alternative assumptions regarding the persistence of the inflation target shock. However, the benefits of transparency are larger when the inflation target shocks are more persistent. The smaller benefit of communication when the inflation target is not very persistent reflects the fact that in this situation the responses of the economy to an inflation target shock and a transitory policy shock are quite similar. Thus, the public's parsing of the sources of the shock has little effect on inflation and output and therefore on the central bank loss.

\subsection{Possible Public Confusion Regarding the Interest Rate Projections}

One concern about central bank provision of interest rate projections is that private agents may misconstrue the accuracy of these projections or view them as unconditional commitments of future policy actions on the part of the central bank. If private agents underreact to interest rate projections, the effects and usefulness of those projections would be more muted than reported

above. A greater concern is that private agents might overreact to published statements of central bank intentions and underreact to the information in policy actions, with potentially deleterious effects on the economy. Such misperceptions of the quality of the central bank projections cannot be part of a long-run equilibrium because agents will eventually deduce the true value of central bank information. Nonetheless, it is conceivable that misperceptions of the noise in the central bank published projections could persist for a significant period of time and therefore be a problem during a transition period following the initial publication of interest rate projections. For this reason, we consider the effects of public confusion as to the degree of transmission noise in central bank rate projections.

If the public systematically underestimates the accuracy of the central bank interest rate projections, then the benefits of central bank communication are muted. The dashed line in Figure 6 shows the central bank losses for different degrees of noise in the central bank projections, where the public filters the incoming information from policy actions and interest rate 
projections and believes that the central bank is sending a signal with $\sigma_{z}=0.25$. The portion of the curve corresponding to values of $\sigma_{z}$ between 0 and 0.25 is nearly flat, indicating that achieving the benefits of central bank communication of rate projections depends critically on the public's believing in the quality of the signal.

Interestingly, in the intermediate case where the public only moderately overestimates the accuracy of the central bank's signal, the central bank loss is actually lower than if the public had correctly assessed the degrees of transmission noise. Thus, for a given degree of transmission noise, the central bank loss is reduced when private agents inefficiently use information in forming expectations. This finding illustrates the more general point that there does not exist an exact universal correspondence between the alignment of private and public expectations and the minimization of the central bank loss. ${ }^{29}$ Under certain conditions, systematic expectational errors can be beneficial to the achievement of the central bank's goals, while in other cases such errors can interfere with the achievement of those goals. Nonetheless, it is worth stressing that in the examples considered here we find that the central bank loss is minimized when the central bank is perfectly transparent, that is, $\sigma_{z}=0$.

If the public severely overestimates the accuracy of central bank signals, then publishing interest rate projections can be counterproductive until private agents realize their misperception of the accuracy of central bank signals. As seen in the figure, if the true value of $\sigma_{z}$ exceeds about 1.25 while the public believes it to be 0.25 , the central bank loss exceeds that which would occur if the central bank did not publish interest rate projections at all. Under this condition, the public's excessive response to the central bank's noisy signal introduces added noise to the public's estimate of the inflation target and this noise causes unwelcome fluctuations in inflation and output.

The potential for misperceptions of the accuracy of the interest rate projections suggests that an important part of such communication is to avoid sending highly noisy signals of future policy intentions that confuse markets. Indeed, concern that communication of policy intentions was doing more harm than good appears to have been behind the FOMC's abandonment of

\footnotetext{
${ }^{29}$ It is possible to devise other examples where an improved alignment of private and central bank expectations increases the central bank loss. For example, if one allows for both a transitory shock to the true inflation target that has a significantly higher variance than either the persistent inflation target or the policy shocks, then either partial transparency or even no transparency can be optimal. This occurs because the public puts some probability that any realized shock is highly persistent, which causes inflation to rise more and the output gap to move less than for a transitory shock, both desirable responses if the source of the shock is a transitory disturbance to the inflation target. Such an example is not realistic, but illustrates the general point that has been made repeatedly in the literature: transparency can be a double-edged sword.
} 
policy guidance in 1999, as discussed above. But, in the cases of the Reserve Bank of New Zealand and the Norges Bank, publication of interest rate projections has not led to excessive or counterproductive market reactions. Moreover, as evidenced by the deviations of market expectations from the RBNZ interest rate projections illustrated in Figure 1, it is clear that market participants do not view the projections as unconditional commitments, nor do they forsake independent analysis of economic conditions and forecasting of policy.

\section{Conclusion}

Indirect signaling of future policy intentions has been the overwhelming choice of central banks in the past. Recently, however, some central banks, including the Fed, have revealed some information to the public about their future policy intentions. However, only two central banks, the RBNZ and the Norges Bank, have gone so far as to provide explicit quantitative forecasts of the policy expectations. The existing theoretical literature has not focused on transparency with regard to interest rate projections, nor has it reached firm conclusions regarding the optimal degree of central bank transparency in general. In our theoretical analysis, we find that central bank communication of interest rate projections can better align the public's and the central bank's expectations and this better alignment of expectations generally leads to improvements in macroeconomic performance.

Although our results provide some support for the argument that the better alignment of expectations improves performance, our analysis also highlights some of the pitfalls that may accompany publishing interest rate projections. An important concern is that the public would misconstrue the central bank communication as providing an unconditional commitment or may put too much weight on the information from the central bank communication relative to other sources of information. We find that the latter concern, if realized, could have costs in terms of macroeconomic stabilization and could even cause performance to worsen relative to the case of no central bank communication. These results underline the need for a well-developed central bank communications strategy that mitigates such problems by highlighting both the conditionality and uncertainty regarding interest rate projections. 
Table 1

Forward-Looking Language in Statements Issued after FOMC Meetings

(All FOMC meetings from May 1999 to June 2006)

\begin{tabular}{|c|c|c|}
\hline $\begin{array}{l}\text { Date of } \\
\text { meeting }\end{array}$ & $\begin{array}{c}\text { Funds } \\
\text { rate }\end{array}$ & Forward-looking language in FOMC policy statement \\
\hline 05/18/1999 & 4.75 & $\begin{array}{l}\text { ". . . the Committee was concerned about the potential for a buildup } \\
\text { of inflationary imbalances that could undermine the favorable performance } \\
\text { of the economy and therefore adopted a directive that is tilted toward the } \\
\text { possibility of a firming in the stance of monetary policy." }\end{array}$ \\
\hline 06/30/1999 & 5.00 & $\begin{array}{l}\text { ". . . the FOMC has chosen to adopt a directive that includes no } \\
\text { predilection about near-term policy action." }\end{array}$ \\
\hline 08/24/1999 & 5.25 & $\begin{array}{l}\text { ". . . the directive the Federal Open Market Committee adopted is } \\
\text { symmetrical with regard to the outlook for policy over the near term." }\end{array}$ \\
\hline $10 / 05 / 1999$ & 5.25 & $\begin{array}{l}\text { ". . . the Committee adopted a directive that was biased toward a } \\
\text { possible firming of policy going forward. Committee members } \\
\text { emphasized that such a directive did not signify a commitment to } \\
\text { near-term action." }\end{array}$ \\
\hline $11 / 16 / 1999$ & 5.50 & $\begin{array}{l}\text { ". . . the directive the Federal Open Market Committee adopted is } \\
\text { symmetrical with regard to the outlook for policy over the near term." }\end{array}$ \\
\hline $12 / 21 / 1999$ & 5.50 & $\begin{array}{l}\text { ". . . the Committee decided to adopt a symmetric directive in order } \\
\text { to indicate that the focus of policy in the intermeeting period must be } \\
\text { ensuring a smooth transition into the Year 2000." }\end{array}$ \\
\hline $02 / 02 / 2000$ & 5.75 & $\begin{array}{l}\text { ". . . the Committee believes the risks are weighted mainly toward } \\
\text { conditions that may generate heightened inflation pressures in the } \\
\text { foreseeable future." }\end{array}$ \\
\hline $03 / 31 / 2000$ & 6.00 & Same as $02 / 02 / 2000$. \\
\hline $05 / 16 / 2000$ & 6.50 & Same as 02/02/2000. \\
\hline $06 / 28 / 2000$ & 6.50 & Same as $02 / 02 / 2000$. \\
\hline $10 / 03 / 2000$ & 6.50 & Same as $02 / 02 / 2000$. \\
\hline $11 / 15 / 2000$ & 6.50 & Same as $02 / 02 / 2000$ \\
\hline $12 / 19 / 2000$ & 6.50 & $\begin{array}{l}\text { ". . . the Committee consequently believes the risks are weighted } \\
\text { mainly toward conditions that may generate economic weakness in the } \\
\text { foreseeable future." }\end{array}$ \\
\hline $01 / 03 / 2001$ & 6.50 & Same as 12/19/2000. \\
\hline $01 / 31 / 2001$ & 5.50 & Same as $12 / 19 / 2000$. \\
\hline $03 / 20 / 2001$ & 5.00 & Same as $12 / 19 / 2000$ \\
\hline 04/18/2001 & 4.50 & Same as 12/19/2000. \\
\hline $05 / 15 / 2001$ & 4.00 & Same as $12 / 19 / 2000$ \\
\hline
\end{tabular}




\begin{tabular}{|c|c|c|}
\hline $06 / 27 / 2001$ & 3.75 & Same as $12 / 19 / 2000$ \\
\hline 08/21/2001 & 3.50 & Same as $12 / 19 / 2000$ \\
\hline 09/17/2001 & 3.00 & Same as $12 / 19 / 2000$ \\
\hline $10 / 02 / 2001$ & 2.50 & Same as $12 / 19 / 2000$ \\
\hline $11 / 06 / 2001$ & 2.00 & Same as $12 / 19 / 2000$ \\
\hline $12 / 11 / 2001$ & 1.75 & Same as $12 / 19 / 2000$ \\
\hline $01 / 30 / 2002$ & 1.75 & Same as $12 / 19 / 2000$ \\
\hline 03/19/2002 & 1.75 & $\begin{array}{l}\text { ". . . the Committee believes that, for the foreseeable future, . . . } \\
\text { the risks are balanced with respect to the prospects for both goals." }\end{array}$ \\
\hline $05 / 07 / 2002$ & 1.75 & Same as $03 / 19 / 2002$ \\
\hline $06 / 26 / 2002$ & 1.75 & Same as 03/19/2002. \\
\hline 08/13/2002 & 1.75 & $\begin{array}{l}\text { ". . . the Committee believes that, for the foreseeable future, . . . } \\
\text { the risks are weighted mainly toward conditions that may generate } \\
\text { economic weakness." }\end{array}$ \\
\hline $09 / 24 / 2002$ & 1.75 & Same as 08/13/2002. \\
\hline $11 / 06 / 2002$ & 1.25 & $\begin{array}{l}\text { ". . . the Committee believes that . . . the risks are balanced with } \\
\text { respect to the prospects for both goals for the foreseeable future." }\end{array}$ \\
\hline $12 / 10 / 2002$ & 1.25 & Same as $11 / 06 / 2002$ \\
\hline $01 / 29 / 2003$ & 1.25 & Same as $11 / 06 / 2002$ \\
\hline $03 / 18 / 2003$ & 1.25 & $\begin{array}{l}\text { "In light of the unusually large uncertainties clouding the geopolitical } \\
\text { situation . . . the Committee does not believe it can usefully characterize } \\
\text { the current balance of risks . . ." }\end{array}$ \\
\hline $05 / 06 / 2003$ & 1.25 & $\begin{array}{l}\text { ". . . the Committee perceives that over the next few quarters the } \\
\text { upside and downside risks to the attainment of sustainable growth are } \\
\text { roughly equal. In contrast, over the same period, the probability of an } \\
\text { unwelcome substantial fall in inflation, though minor, exceeds that of a } \\
\text { pickup in inflation from its already low level. The Committee believes } \\
\text { that, taken together, the balance of risks to achieving its goals is } \\
\text { weighted toward weakness over the foreseeable future." }\end{array}$ \\
\hline $06 / 25 / 2003$ & 1.00 & Similar to $05 / 06 / 2003$ \\
\hline $08 / 12 / 2003$ & 1.00 & $\begin{array}{l}\text { ". . . the Committee believes that policy accommodation can be } \\
\text { maintained for a considerable period." }\end{array}$ \\
\hline $09 / 16 / 2003$ & 1.00 & Same as $08 / 12 / 2003$. \\
\hline $10 / 28 / 2003$ & 1.00 & Same as 08/12/2003. \\
\hline $12 / 09 / 2003$ & 1.00 & Same as 08/12/2003. \\
\hline $01 / 28 / 2004$ & 1.00 & $\begin{array}{l}\text { "With inflation quite low and resource use slack, the Committee } \\
\text { believes that it can be patient in removing its policy accommodation." }\end{array}$ \\
\hline
\end{tabular}




\begin{tabular}{|c|c|c|}
\hline $03 / 16 / 2004$ & 1.00 & Same as $01 / 28 / 2004$ \\
\hline $05 / 04 / 2004$ & 1.00 & $\begin{array}{l}\text { ". . . the Committee believes that policy accommodation can be } \\
\text { removed at a pace that is likely to be measured." }\end{array}$ \\
\hline 06/30/2004 & 1.25 & Same as $05 / 04 / 2004$ \\
\hline 08/10/2004 & 1.50 & Same as $05 / 04 / 2004$ \\
\hline $09 / 21 / 2004$ & 1.75 & Same as $05 / 04 / 2004$ \\
\hline $11 / 10 / 2004$ & 2.00 & Same as $05 / 04 / 2004$ \\
\hline $12 / 14 / 2004$ & 2.25 & Same as $05 / 04 / 2004$ \\
\hline $02 / 02 / 2005$ & 2.50 & Same as 05/04/2004. \\
\hline $03 / 22 / 2005$ & 2.75 & Same as $05 / 04 / 2004$ \\
\hline $05 / 03 / 2005$ & 3.00 & Same as $05 / 04 / 2004$ \\
\hline $06 / 30 / 2005$ & 3.25 & Same as $05 / 04 / 2004$ \\
\hline 08/09/2005 & 3.50 & Same as $05 / 04 / 2004$ \\
\hline $09 / 20 / 2005$ & 3.75 & Same as 05/04/2004. \\
\hline $11 / 02 / 2005$ & 4.00 & Same as 05/04/2004. \\
\hline $12 / 13 / 2005$ & 4.25 & $\begin{array}{l}\text { "The Committee judges that some further policy firming is likely to be } \\
\text { needed to keep the risks to the attainment of both sustainable economic } \\
\text { growth and price stability roughly in balance." }\end{array}$ \\
\hline $01 / 31 / 2006$ & 4.50 & $\begin{array}{l}\text { "The Committee judges that some further policy firming may be } \\
\text { needed to keep the risks to the attainment of both sustainable economic } \\
\text { growth and price stability roughly in balance." }\end{array}$ \\
\hline $03 / 28 / 2006$ & 4.75 & Same as $01 / 31 / 2006$ \\
\hline $05 / 10 / 2006$ & 5.00 & $\begin{array}{l}\text { "The Committee judges that some further policy firming may yet be } \\
\text { needed to address inflation risks . . ." }\end{array}$ \\
\hline $06 / 29 / 2006$ & 5.25 & ". . . the Committee judges that some inflation risks remain." \\
\hline
\end{tabular}

Note: The date of each FOMC meeting or conference call (or the second day of a two-day meeting) is given along with the intended target level of the federal funds rate prevailing after the meeting and the salient forward-looking language in the post-meeting statement about the future policy inclination or the balance of economic risks. 


\section{References}

Archer, David (2005), "Central Bank Communication and the Publication of Interest Rate Projections," manuscript, Bank of International Settlements.

Bernanke, Ben (2004), "Central Bank Talk and Monetary Policy," speech, October 7, 2004, Federal Reserve Board.

Bernanke, Ben, Vincent R. Reinhart and Brian P. Sack (2004), "Monetary Policy Alternatives at the Zero Bound: An Empirical Assessment," Brookings Papers on Economic Activity 2, 1-100.

Blinder, Alan S. (1998), Central Banking in Theory and Practice, MIT Press, Cambridge, MA.

Blinder, Alan S. (2004), The Quiet Revolution: Central Banking Goes Modern, Yale University Press, New Haven, CT.

Bomfim, Antulio, and Glenn D. Rudebusch (2000), "Opportunistic and Deliberate Disinflation Under Imperfect Credibility," Journal of Money, Credit, and Banking 32, 707-721.

Carpenter, Seth (2004), "Transparency and Monetary Policy: What Does the Academic Literature Tell Policymakers?" Finance and Economics Discussion Series, 2004-35, Federal Reserve Board.

Cogley, Timothy, and Argia M. Sbordone (2005), "A Search for a Structural Phillips Curve," Federal Reserve Bank of New York Staff Reports 203.

Eggertsson, Gauti B., and Michael Woodford (2003), "The Zero Bound on Interest Rates and Optimal Monetary Policy," Brookings Papers on Economic Activity 1, 193-233.

Erceg, Christopher J., and Andrew T, Levin (2003), "Imperfect Credibility and Inflation Persistence," Journal of Monetary Economics 50(4), 915-944.

Faust, Jon, and Lars E. O. Svensson (2001), "Transparency and Credibility: Monetary Policy with Unobservable Goals," International Economic Review 42, 369-397.

Faust, Jon, and Eric M. Leeper (2005), "Forecasts and Inflation Reports: An Evaluation," prepared for the Sveriges Riksbank conference "Inflation Targeting: Implementation, Communication and Effectiveness," June 11-12 2005.

Fuhrer, Jeffrey C., and Glenn D. Rudebusch (2004), "Estimating the Euler Equation for Output," Journal of Monetary Economics 51, 1133-1153.

Geraats, Petra M. (2002), "Central Bank Transparency," Economic Journal 112, 532-565.

Geraats, Petra M. (2005), "Transparency and Reputation: The Publication of Central Bank Forecasts," Topics in Macroeconomics 5, 1-26.

Goodfriend, Marvin (1986), "Monetary Mystique: Secrecy and Central Banking," Journal of Monetary Economics 17, 63-92.

Goodhart, Charles A.E. (2001), "Monetary Transmission Lags and the Formulation of the Policy Decision on Interest Rates," Federal Reserve Bank of St. Louis Review July/August, 165-181. 
Gürkaynak, Refet S., Brian Sack, and Eric T. Swanson (2005a), "Do Actions Speak Louder than Words? The Response of Asset Prices to Monetary Policy Actions and Statements," International Journal of Central Banking 1, 55-93.

Gürkaynak, Refet S., Brian Sack, and Eric T. Swanson (2005b), "The Sensitivity of LongTerm Interest Rates: Evidence and Implications for Macroeconomic Models," American Economic Review 95:1, 425-436.

Harvey, Andrew C. (1989), Forecasting, Structural Time Series Models and the Kalman Filter, Cambridge University Press, Cambridge, UK.

Hellwig, Christian (2005), "Heterogeneous Information and the Welfare Effects of Public Information Disclosures," manuscript, University of California, Los Angeles.

Hördahl, Peter, Oreste Tristani, and David Vestin (2006), "A Joint Econometric Model of Macroeconomic and Term Structure Dynamics," Journal of Econometrics 131, 405-444.

King, Mervyn. 2006. Speech at the Lord Mayor's banquet for bankers and merchants, London, England, June 21.

Kohn, Donald L. (2005), "Central Bank Communication" speech, January 9, Federal Reserve Board.

Kohn, Donald L., and Brian Sack (2004), "Central Bank Talk: Does It Matter and Why?" in Macroeconomics, Monetary Policy, and Financial Stability, Bank of Canada.

Kozicki, Sharon, and Peter A. Tinsley (2001), "Shifting Endpoints in the Term Structure of Interest Rates," Journal of Monetary Economics 47, 613-652.

Lange, Joe, Brian Sack and William Whitesell (2003), "Anticipations of Monetary Policy in Financial Markets," Journal of Money, Credit, and Banking 35:6, 889-909.

Leitemo, Kai (2003), "Targeting Inflation by Constant-Interest-Rate Forecasts," Journal of Money, Credit and Banking 35, 609-626.

McGough, Bruce, Glenn D. Rudebusch, and John C. Williams (2005), "Using a Long-Term Interest Rate as the Monetary Policy Instrument," Journal of Monetary Economics 52, 855-879.

Miller, Rich (2005), "The Fed May Be Talking Too Freely," Business Week, March 24.

Mishkin, Frederic S. (2004), "Can Central Bank Transparency Go Too Far," in The Future of Inflation Targeting, Reserve Bank of Australia, 48-66.

Morris, Stephen, and Hyun S. Shin (2002), "Social Value of Public Information," American Economic Review 92:5, 1521-1534.

Morris, Stephen, and Hyun S. Shin (2005), "Central Bank Transparency and the Signal Value of Prices," Brookings Papers on Economic Activity 2, 1-66.

Oda, Nobuyuki, and Kazuo Ueda (2005), “The Effects of the Bank of Japan's Zero Interest Rate Commitment and Quantitative Monetary Easing on the Yield Curve: A Macro-Finance Approach," Bank of Japan Working Paper No. 05-E-6. 
Orphanides, Athanasios, and John C. Williams, "Imperfect Knowledge, Inflation Expectations, and Monetary Policy," in Ben S. Bernanke and Michael Woodford (ed.) The InflationTargeting Debate, Chicago: University of Chicago Press, 2005, 201-234.

Poole, William (2005a) "Communicating the Fed's Policy Stance." speech, November 30, Federal Reserve Bank of St. Louis.

Poole, William (2005b) "How Should the Fed Communicate?" speech, April 2, Federal Reserve Bank of St. Louis.

Qvigstad, Jan F. (2005), "When Does an Interest Rate Path 'Look Good'? Criteria for an Appropriate Future Interest Rate Path - A Practician's Approach," Norges Bank Staff Memo No. 2005/6.

Reifschneider, David, and John C. Williams (2000), "Three Lessons for Monetary Policy in a Low Inflation Era," Journal of Money, Credit and Banking 32:4, 936-966.

Roca, Mauro (2005), "Transparency and Monetary Policy with Imperfect Common Knowledge," manuscript, Columbia University.

Rudebusch, Glenn D. (1995), "Federal Reserve Interest Rate Targeting, Rational Expectations, and the Term Structure," Journal of Monetary Economics 24, 245-274.

Rudebusch, Glenn D. (2002), "Term Structure Evidence on Interest Rate Smoothing and Monetary Policy Inertia," Journal of Monetary Economics 49, 1161-1187.

Rudebusch, Glenn D. (2006), "Monetary Policy Inertia: Fact of Fiction?," International Journal of Central Banking, forthcoming.

Rudebusch, Glenn D., and Lars E.O. Svensson (1999), "Policy Rules for Inflation Targeting," in John B. Taylor (ed.), Monetary Policy Rules, (Chicago: Chicago University Press), 203-246.

Rudebusch, Glenn D., and Tao Wu (2004), "A Macro-Finance Model of the Term Structure, Monetary Policy, and the Economy," Working Paper.

Rudebusch, Glenn D., and Tao Wu (2006), "Accounting for a Shift in Term Structure Behavior with No-Arbitrage and Macro-Finance Models," manuscript, forthcoming in the Journal of Money, Credit, and Banking.

Schlesinger, Jacob M. (2000), "Fed Replaces 'Bias' Stance with 'Risks' Outlook," Wall Street Journal, January 20, A2.

Svensson, Lars E. O. (1997), "Inflation Forecast Targeting: Implementing and Monitoring Inflation Targets," European Economic Review 41, 1111-1146.

Svensson, Lars E.O. (2003), "What is Wrong with Taylor Rules? Using Judgement in Monetary Policy through Targeting Rules," Journal of Economic Literature 41, 426-477.

Svensson, Lars E.O. (2005a), "Monetary Policy with Judgment: Forecast Targeting," International Journal of Central Banking 1, 1-54. 
Svensson, Lars E.O. (2005b), "Optimal Inflation Targeting: Further Developments of Inflation Targeting," manuscript, Princeton University.

Svensson, Lars E.O. (2006a), "Social Value of Public Information: Comment: Morris and Shin (2002) Is Actually Pro Transparency, Not Con," American Economic Review, 96:1, $448-452$.

Svensson, Lars E.O. (2006b), "The Instrument-Rate Projection under Inflation Targeting: The Norwegian Example," manuscript, Princeton University.

Swanson, Eric (2006), "Have Increases in Federal Reserve Transparency Improved Private Sector Forecasts of Short-Term Interest Rates?" Journal of Money, Credit and Banking, forthcoming.

Thornton, Daniel L., and David C. Wheelock (2000), "A History of the Asymmetric Policy Directive," Federal Reserve Bank of St. Louis Review September/October, 1-16.

Trichet, Jean-Claude (2006), "The State of the Economy: Overcoming Key Challenges to Sustainable Economic Growth," speech, February 6, European Central Bank.

Walsh, Carl E. (2005), "Optimal Transparency Under Flexible Inflation Targeting," manuscript, University of California, Santa Cruz.

Williams, John C. (2006), "Monetary Policy in a Low Inflation Economy with Learning," manuscript Federal Reserve Bank of San Francisco.

Woodford, Michael (2003), Interest and Prices: Foundations of a Theory of Monetary Policy, Princeton: Princeton University Press.

Woodford, Michael (2005), "Central-Bank Communication and Policy Effectiveness," in The Greenspan Era: Lessons for the Future, Federal Reserve Bank of Kansas City, 399-474. 


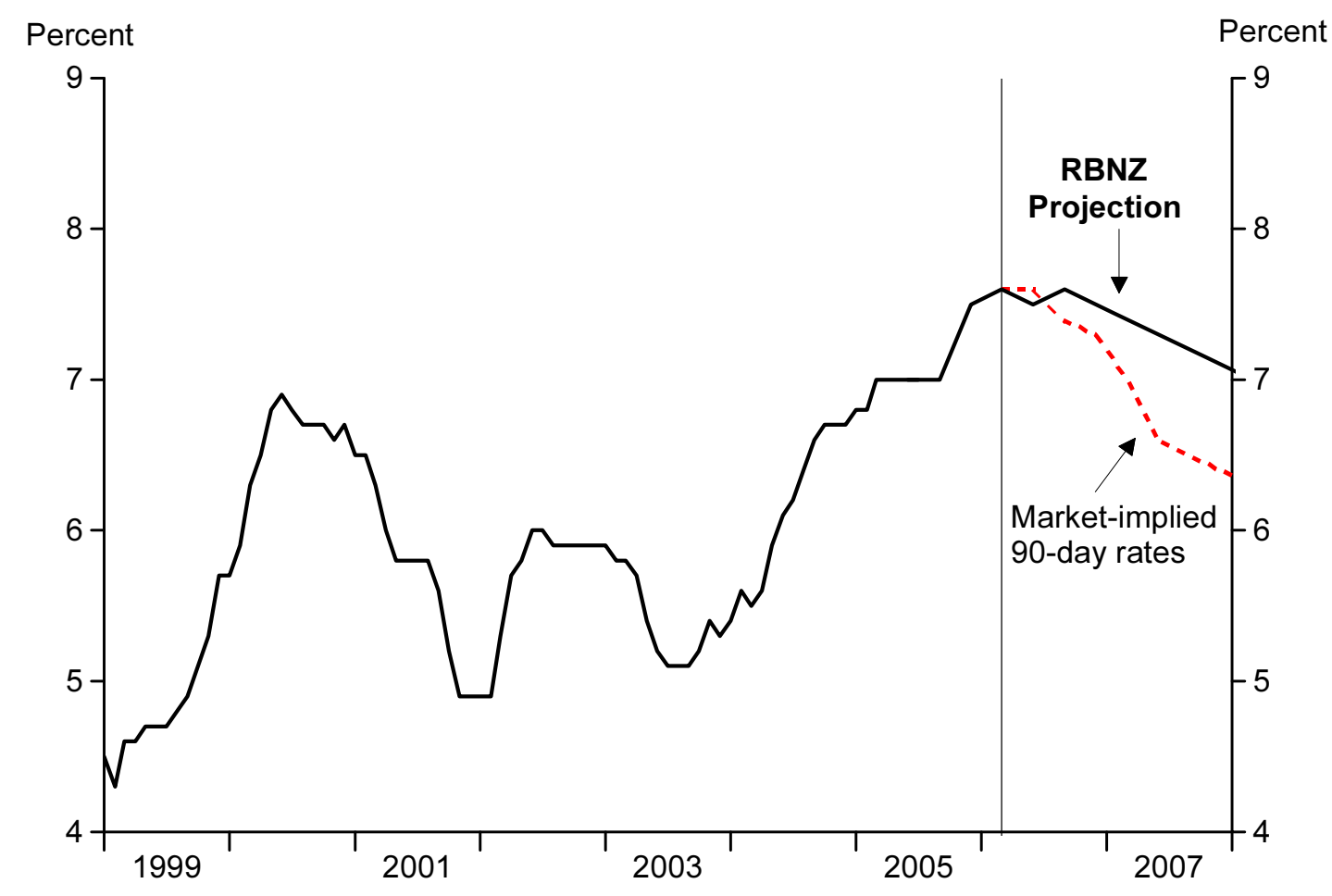

Figure 1: RBNZ projection of short-term interest rate

Note: The solid line shows the historical data and the RBNZ's March 2006 baseline projection for the 90-day interest rate (which is closely linked to the official policy interest rate). The dashed line shows expected rates in financial markets. Source: RBNZ March 2006 Monetary Policy Statement, Figure 2.6 


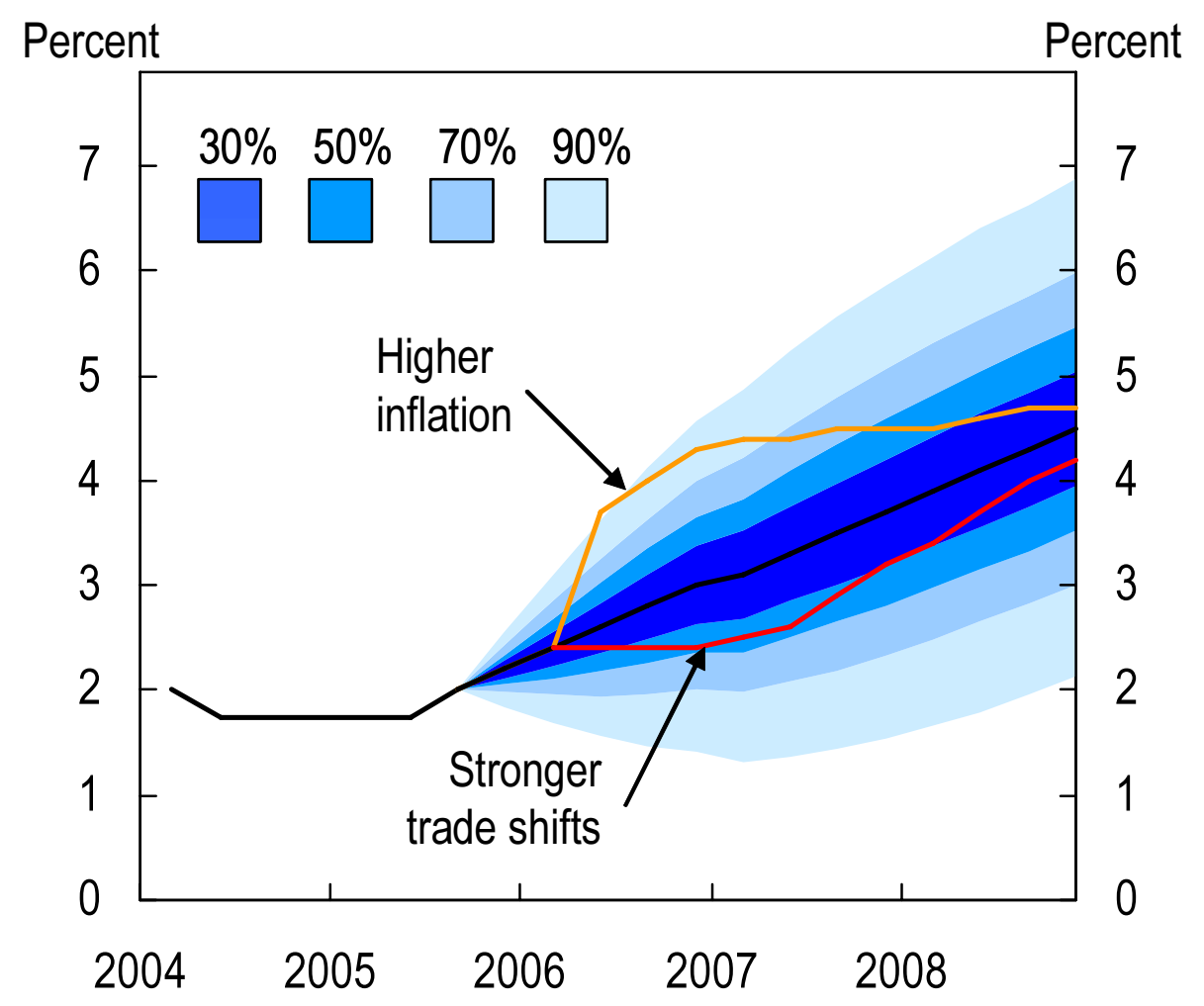

Figure 2: Norges Bank projection of its policy interest rate

Note: The dark central line is the recent past and the Norges Bank's November 2005 baseline projection of the policy interest rate ("sight deposit rate") over the next three years. The shaded regions represent 30,50, 70, and 90 percent confidence intervals around the baseline projection. Projected policy rate paths under two separate alternate scenarios are also shown. Source: Norges Bank November 2005 Inflation Report, Chart 1.9a. 


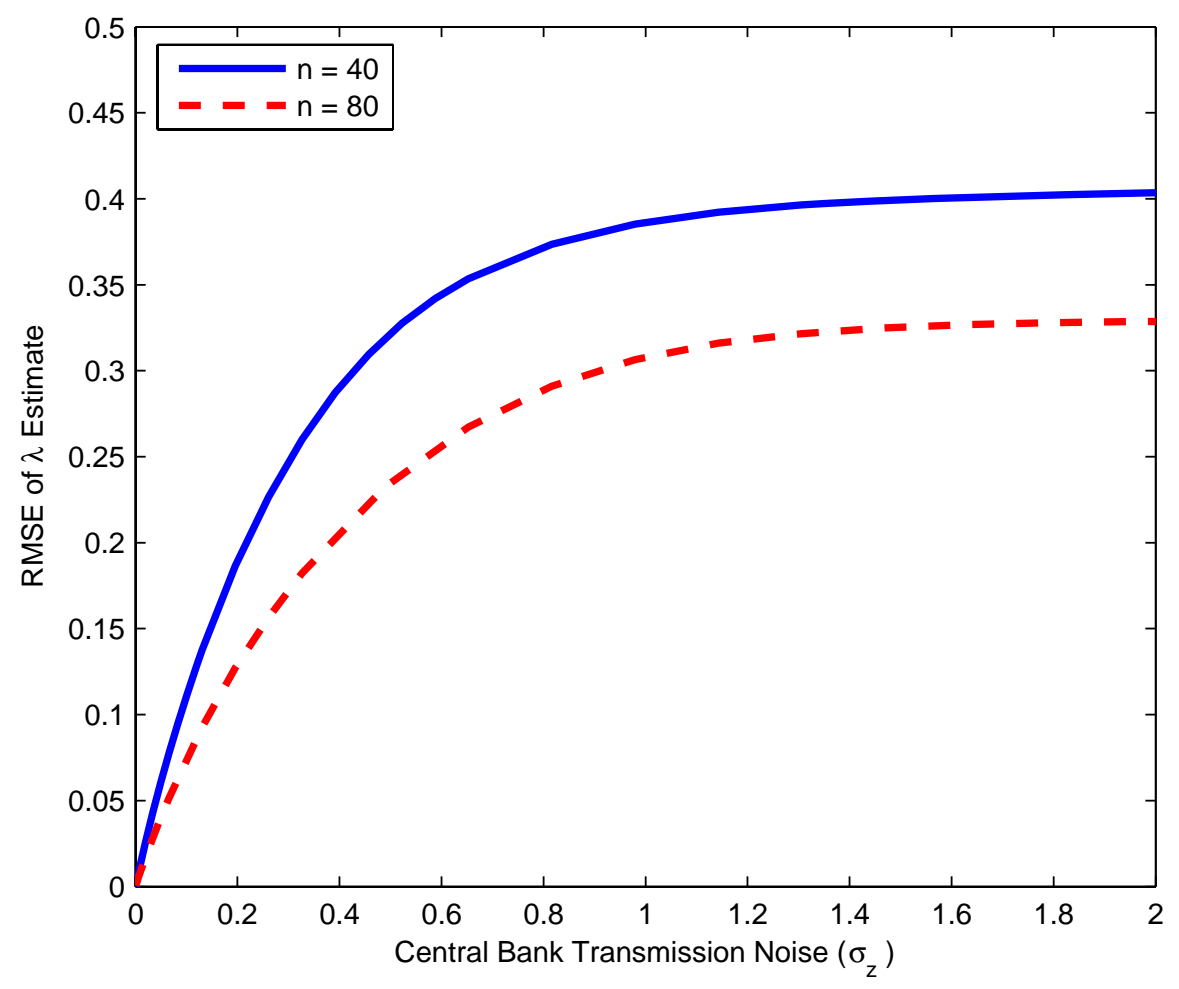

Figure 3: Interest Rate Projections and Estimates of $\lambda$ 


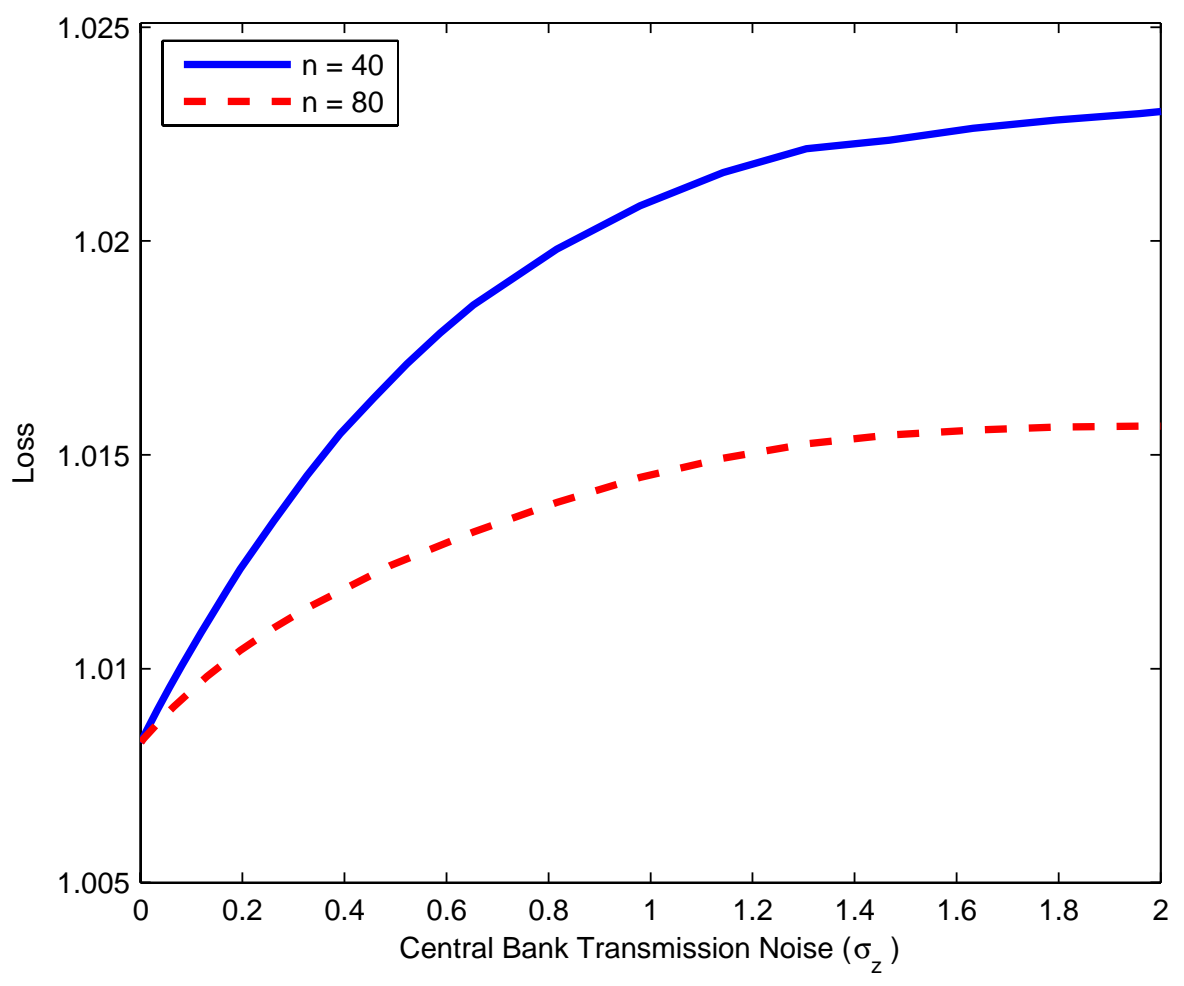

Figure 4: Interest Rate Projections and the Central Bank Loss 


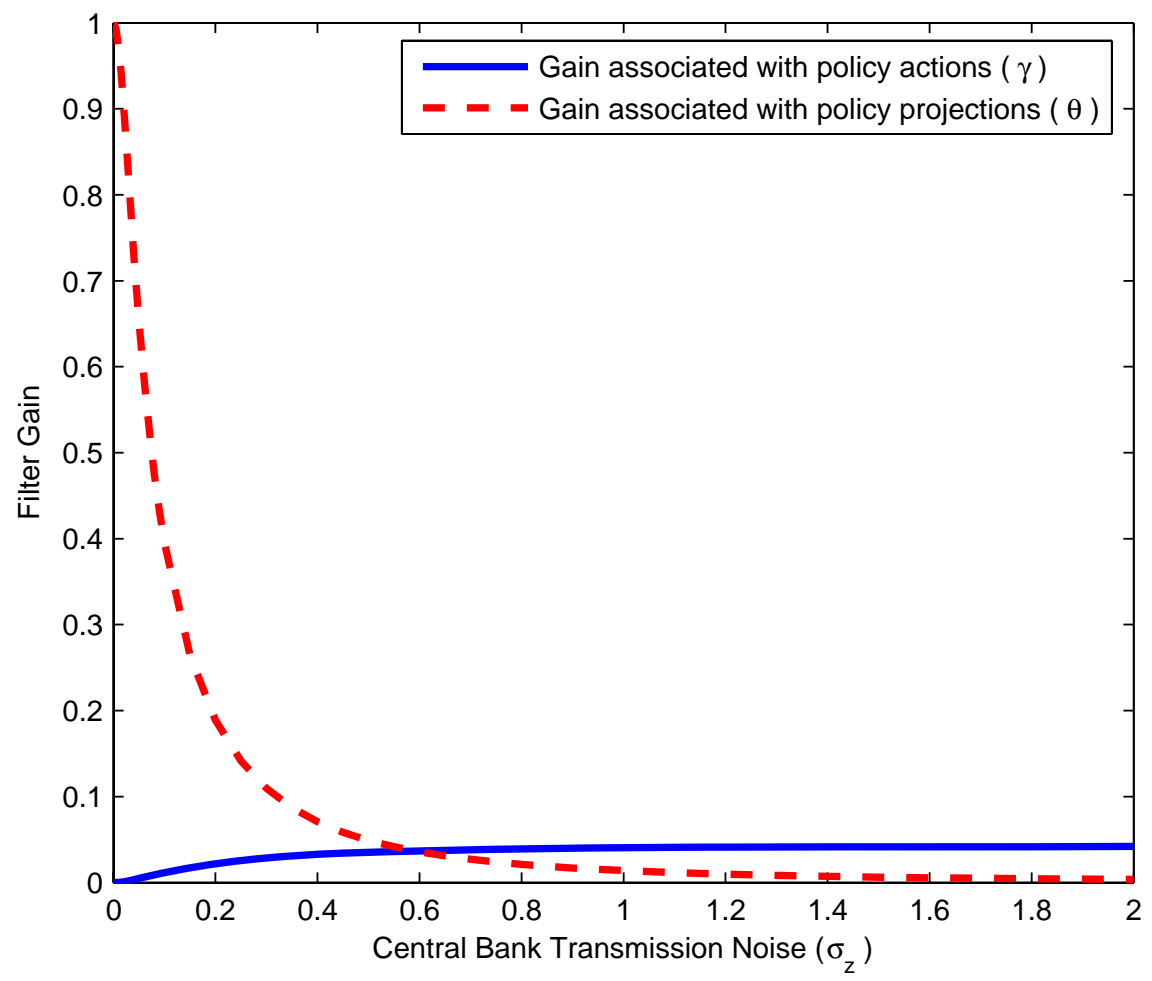

Figure 5: Inflation Target Uncertainty and the Optimal Use of Information 


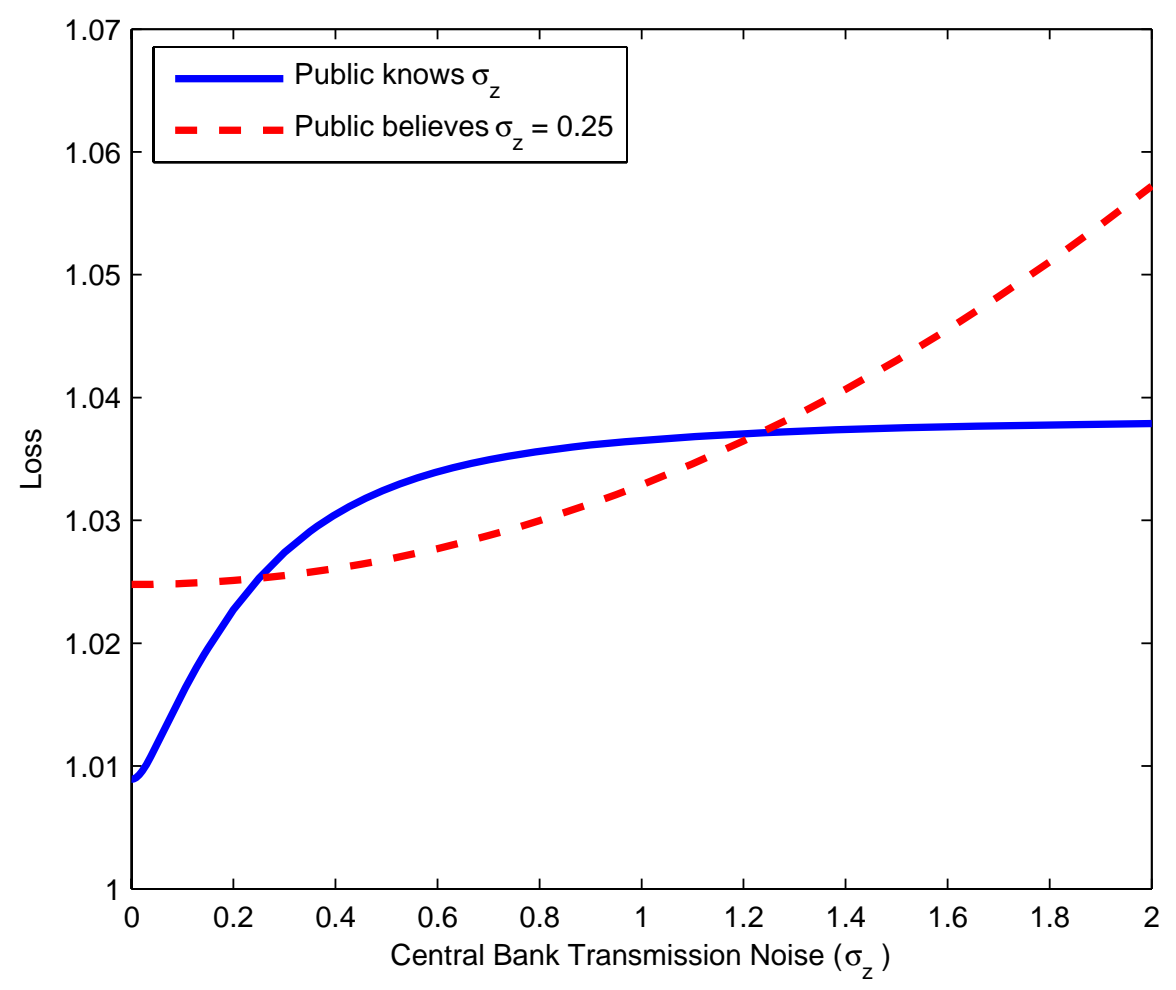

Figure 6: Inflation Target Uncertainty and the Central Bank Loss 